Check for updates

Cite this: Phys. Chem. Chem. Phys., 2018, 20, 10569

Received 12th December 2017 Accepted 13th March 2018

DOI: $10.1039 / c 7 c p 08331 a$

\section{Coupling free radical catalysis, climate change, and human health}

\author{
J. G. Anderson (D) *abc and C. E. Clapp (D) ${ }^{a}$
}

\begin{abstract}
We present the chain of mechanisms linking free radical catalytic loss of stratospheric ozone, specifically over the central United States in summer, to increased climate forcing by $\mathrm{CO}_{2}$ and $\mathrm{CH}_{4}$ from fossil fuel use. This case directly engages detailed knowledge, emerging from in situ aircraft observations over the polar regions in winter, defining the temperature and water vapor dependence of the kinetics of heterogeneous catalytic conversion of inorganic chlorine $\left(\mathrm{HCl}\right.$ and $\left.\mathrm{ClONO}_{2}\right)$ to free radical form $(\mathrm{ClO})$. Analysis is placed in the context of irreversible changes to specific subsystems of the climate, most notably coupled feedbacks that link rapid changes in the Arctic with the discovery that convective storms over the central US in summer both suppress temperatures and inject water vapor deep into the stratosphere. This places the lower stratosphere over the US in summer within the same photochemical catalytic domain as the lower stratosphere of the Arctic in winter engaging the risk of amplifying the rate limiting step in the $\mathrm{ClO}$ dimer catalytic mechanism by some six orders of magnitude. This transitions the catalytic loss rate of ozone in lower stratosphere over the United States in summer from HOx radical control to $\mathrm{ClOx}$ radical control, increasing the overall ozone loss rate by some two orders of magnitude over that of the unperturbed state. Thus we address, through a combination of observations and modeling, the mechanistic foundation defining why stratospheric ozone, vulnerable to increased climate forcing, is one of the most delicate aspects of habitability on the planet.
\end{abstract}

\section{Recasting the climate case:} mechanisms that set the time scale for instability of and irreversible changes to the climate structure

1.1 Distinguishing between heat flow into subsystems of the climate structure and changes in the global mean surface temperature

Coupling free radical catalysis, climate change, and human health requires a reframing of the discussion of climate response by first emphasizing the fact that the term "Global Warming" does not capture the imperative for what is actually occurring to the climate structure. Increases in the global mean temperature (to which global warming refers) of $1{ }^{\circ} \mathrm{C}$ in the last few decades carries little imperative. Individuals have little concern for small changes in global average surface temperature. Global average temperature increases are small because $70 \%$ of the Earth's

\footnotetext{
${ }^{a}$ Department of Chemistry and Chemical Biology, Harvard University, Cambridge, MA 02138, USA. E-mail: anderson@huarp.harvard.edu

${ }^{b}$ John A. Paulson School of Engineering and Applied Sciences, Harvard University, Cambridge, MA 02138, USA

${ }^{c}$ Department of Earth and Planetary Sciences, Harvard University, Cambridge, MA 02138, USA
}

surface is covered by oceans with an average depth of $3500 \mathrm{~m}$ resulting in the massive heat capacity of the ocean that in turn strongly suppresses changes in temperature for a given input of heat-heat flow resulting from the trapping of infrared radiation by increasing concentrations of, primarily, $\mathrm{CO}_{2}$ and $\mathrm{CH}_{4}$ from fossil fuel extraction, distribution and combustion. What matters, in fact, is the net flow of heat into subsystems of the climate structure. This inflow of heat leads to irreversible changes in those subsystems that in turn triggers feedbacks that contribute to the instability of the overall climate structure. In this link between climate change and kinetics, we can capture the irreversibility of the climate system on a "potential energy surface" diagram that separates specific climate states. For example, the current climate state (for which there are ice structures in both the northern polar regions and southern polar regions, in addition to ice coverage over the Tibetan Plateau) is distinct from a climate state for which no ice exists in either the northern hemisphere or the southern hemisphere. The paleorecord extending over millions of years clearly demonstrates the existence of both these climate states. ${ }^{1}$ The climate state with no polar ice corresponding to increased $\mathrm{CO}_{2}$ mixing ratios is characterized by a very small temperature difference between the tropics and the polar regions; as well as a moist stratosphere that would lead, as we will see in the second section of this paper, to catastrophic stratospheric ozone loss globally. 




Fig. 1 The current climate state characterized by polar ice systems in both hemispheres, a large temperature gradient between the tropics and the polar regions, in combination with a very dry stratosphere will, as the paleo-record demonstrates, transition to a markedly different climate state at $\mathrm{CO}_{2}$ mixing ratios greater than about $350 \mathrm{ppmv}$. That new climate state, in addition to more intense storm systems, is characterized by a sharply reduced temperature gradient between the tropics and polar regions, the absence of cryo-systems in the Northern Hemisphere, markedly higher sea levels and a moist stratosphere.

That climate state characterized by a moist stratosphere, the elimination of ice systems in both hemispheres, and very little temperature difference between the equator and the polar regions occurs when carbon dioxide levels reach approximately 500 ppm. $^{2}$ Fig. 1 represents these two climate states on a "potential energy" schematic wherein the transition from the current climate state for which we have a very dry stratosphere and a large temperature gradient between the tropics and the polar regions, transitions to a new climate state via the addition of carbon dioxide and methane to the atmosphere. Another important flaw in focusing on the term global warming is that it carries with it the implication of very slow change that can potentially be reversed simply by decreasing the use of fossil fuels as a global energy source. As we will see, the irreversible nature of climate change clearly exposes the fallacy of this approach.

1.2 Example of the importance of feedbacks in subsystems of the climate structure: the rapid loss of Arctic floating ice volume

The clearest manifestation of the importance of tracking heat flow into subsystems of the climate structure is reflected in the rapid changes to the Arctic system that emerge from observations of the remarkably rapid decrease in the volume of permanent floating ice in the Arctic Ocean in the last four decades.

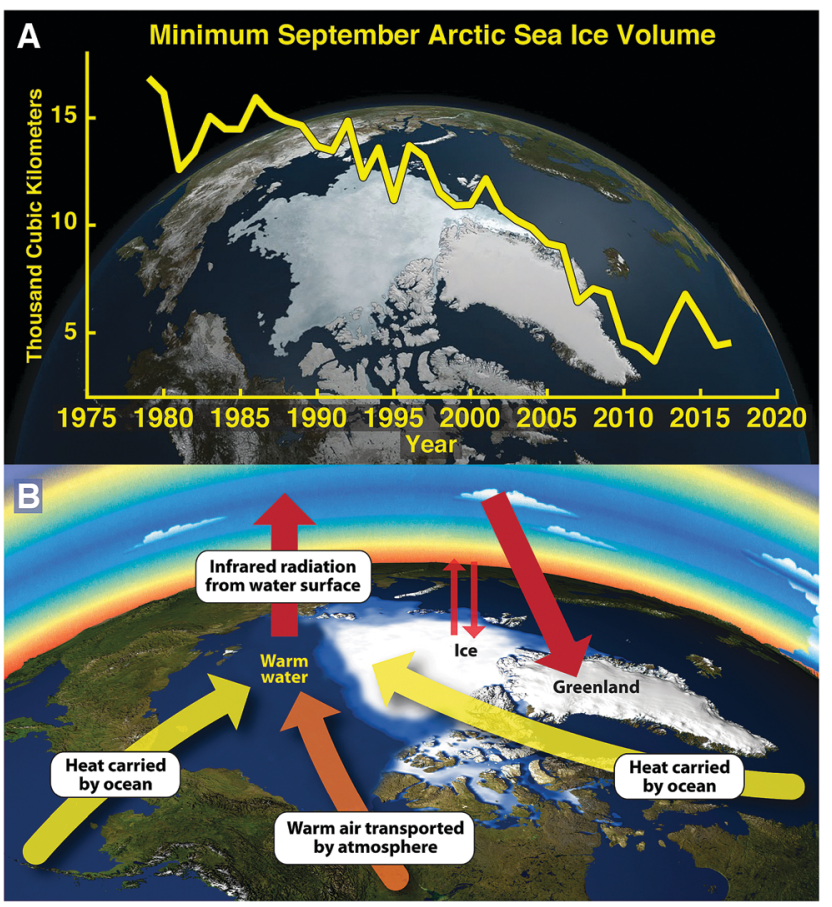

Fig. 2 Perhaps the most dramatic impact on the global climate structure is the rapid loss of permanent floating ice volume in the Arctic Ocean displayed in panel A. Permanent ice refers to the ice volume that remains each year at the end of the summer melt season that has dropped from $17 \times 10^{3} \mathrm{~km}^{3}$ in 1979 to $4 \times 10^{3} \mathrm{~km}^{3}$ in 2016. Panel B delineates the potent feedbacks that serve to set the time scale for the irreversible loss of Arctic floating ice that is reflected in the negative first and second derivatives of the ice volume displayed in panel A. Those feedbacks include the increased heat flow into the Arctic Basin delivered by the inflow of warm sea water from lower latitudes that increases as the ice cap constricts, the increased heat flow into the Arctic Basin delivered by the inflow of warm air as the ice and snow cover in the region surrounding the Arctic Basin is replaced by dark terrestrial vegetation and open ocean, and finally by the marked increase in the input of solar radiation to the surface water of the Arctic Ocean as the ice cap withdraws.

Fig. 2, panel A, summarizes the time evolution of the volume of Arctic floating ice based on the University of Washington Applied Physics Laboratory Polar Ice Observations Modeling and Assimilation (PIOMAS) results released periodically on the PIOMAS website. These important results track the Arctic Ocean ice volume through to the present beginning in 1979 when there was $17 \times 10^{3}$ cubic kilometers of floating ice at the end of the summer melt season (mid-September), referred to as the "permanent ice". The ice volume by mid-September 2017 reveals that the ice volume has decreased to approximately $4 \times 10^{3}$ cubic kilometers-a decrease of $75 \%$ in just 38 years. It is also important to underscore that both the first and second derivative of ice volume as a function of time are strongly negative. This is a direct result, and clear indicator of, the potent positive feedbacks within the Arctic cryo-structure itself.

As we will see in the next section this loss of Arctic permanent ice has major consequences for the overall global climate structure. This raises the immediate question: can the Arctic Ocean lose $75 \%$ of its permanent ice volume and recover to a stable climate state? The answer to this question is clearly no, 
because of the powerful feedbacks in the Arctic system that are represented graphically in Fig. 2, panel B. First of all, as the ice cap over the Arctic Ocean contracts, it allows warm low latitude ocean water to enter the Arctic Basin-in sharp contrast to the case in earlier decades when the Arctic Ice Cap covered the entire Arctic Basin, blocking the inflow of warm surface waters from lower latitudes. In addition, because the atmospheric transport of heat by wind systems entering the Arctic Basin was dramatically decreased by radiative cooling into the low temperature ice and snow fields covering regions surrounding the Arctic, little heat was transported via wind systems into the Arctic Basin. In sharp contrast, with the elimination of ice and snowcover from the region surrounding the Arctic Basin, a large flux of heat into the Arctic Basin results. These are the first two feedbacks that contribute to the increasing rate of disappearance with time of Arctic ice. Another important factor is the albedo effect-that ice and snow reflect $90 \%$ of the incoming summer solar shortwave radiation, whereas the exposed forests of the terrestrial component and the exposed water in the Arctic Ocean absorb $90 \%$ of the incoming shortwave solar radiation. This results primarily and most importantly in the warming of the surface waters of the Arctic Ocean in the summer that rapidly increases the rate of removal of ice. In the 1950s the average depth of the Arctic ice cap covering the Arctic Ocean was about 3.5 meters. Today, in sharp contrast, the average depth of the ice is a mere 1.5 meters which means that that remaining ice is sitting directly in the warm pool heated by the incoming solar radiation in the summertime.

Finally, the structure of the remaining ice is made up of small regions of ice connected via a web of very thin ice. The result is that the surface-to-volume ratio of the ice that remains is much greater than was the case with 3.5 meter thick monolith of ice and the result is that the remaining ice melts much more quickly in the early summer. In addition, the fragile nature of the remaining ice structure means that it is far more susceptible to wind conditions breaking up the remaining ice cover. Thus an impervious, largely immobile ice structure that characterized the Arctic since the last ice age has evolved into a far more delicate and unstable architecture that is rapidly crumbling.

\subsection{Feedbacks within the global climate structure that couple directly to the Arctic}

An important factor in the understanding of the global climate response to increased forcing of the climate by $\mathrm{CO}_{2}$ and $\mathrm{CH}_{4}$ is the cascade of feedbacks that emanate from the loss of ice volume from the Arctic Ocean. This underscores the fact that the Arctic as a system drives key feedbacks within the larger global climate structure. An example of this coupling is displayed in Fig. 3 that we will refer to repeatedly in linking climate change to chemical kinetics. First, as we have already noted, the feedbacks that accelerate the rate of permanent ice loss in the Arctic are comprised of heat transport by the ocean, heat transport by the atmosphere, and the increased absorption of solar radiation by the land and surface waters of the Arctic Basin. The warming surface waters of the Arctic Ocean emit radiation in the infrared (IR) proportional to the fourth power

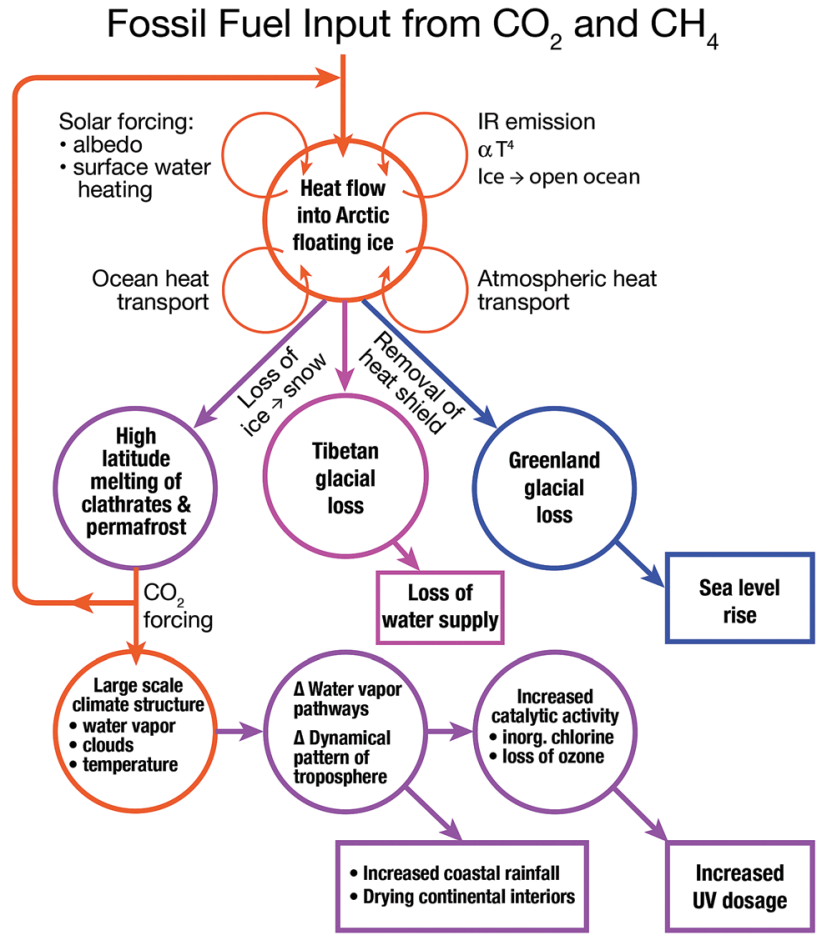

Fig. 3 The cascade of coupled feedbacks that originate in the Arctic include the increasing rate of ice volume loss from the Greenland glacial system that serves to accelerate the rate of sea level rise, the increasing rate of ice volume loss from the Tibetan glacial system that threatens water supplies to China and India, the melting of methane clathrates and permafrost that increase the flux of greenhouse gas release from the Arctic Basin to the atmosphere, the warming surface waters of the world's oceans that intensify and increase the frequency of storm systems. One manifestation of increased storm intensity and frequency is the increasing depth and frequency of storm systems over the central United States in summer with the potential of triggering ozone loss in the stratosphere.

of the temperature and that bathes the entire Arctic Basin with increased infrared flux.

Emanating from the feedbacks within the Arctic Basin itself is a manifold of coupled responses and feedbacks within the global climate structure. First, driven by the rapid warming of the Arctic Basin, is the melting of soil-based carbon reservoirs releasing both carbon dioxide and methane which serves to increasingly force the climate as a result of the trapping of infrared radiation. As we will see in subsequent sections, the decrease in the amount of Arctic ice removes a critical "heat shield" that has protected the Greenland glacial system for the last 120000 years since the last inter-glacial period by suppressing summer temperatures sufficiently to prevent any substantial mass loss of ice. Greenland, because it contains a volume of ice corresponding to $7 \mathrm{~m}$ of sea level rise, is a critically important consideration for forecast models of sea level rise. In contrast, the Tibetan glacial structure provides $65 \%$ of the summer flow of water to China and $90 \%$ of the summer flow of water to India. Just as the Arctic ice structure protects Greenland against melting, so too does the Arctic ice structure contribute to the protection of the Tibetan glacial system from mass loss. 
The next series of feedbacks we consider involve the largescale dynamical changes to the climate structure that is set, in the current climate state, by the temperature difference between the tropical regions and the polar regions. As the loss of Arctic permanent ice occurs, the temperature of the polar regions of the northern hemisphere increase far more rapidly than does the average global surface temperature. This is typically termed the "Arctic Amplification". This Arctic Amplification results in a fundamental shift in the atmosphere's overturning structure that engenders dynamical changes to the atmosphere that shifts climate regions pole-ward in each hemisphere. This implies, for example, the shift of the climate of Northern Africa into the Mediterranean Basin and the shift of the climate of Northern Mexico into the central United States.

A final feedback that will be discussed in the sections that follow involves the increasing surface temperatures of the ocean that leads to increased convective activity in severe storm systems, particularly the intensity of hurricanes and typhoons as well as the intensity or tornadoes and hail storms over the central United States. The increase in the intensity of the convective systems over the Great Plains of the United States in summer, provides the injection of water vapor deep into the stratosphere in July and August each year potentially resulting in the rapid heterogeneous catalytic conversion of inorganic chlorine (primarily $\mathrm{HCl}$ and $\mathrm{ClONO}_{2}$ ) to free radical form, ClO. $^{3,4}$ This is particularly important in the chlorine system resulting in the increase in concentration of the ClO free radical that then engages the direct catalytic removal of ozone just as it does over the Antarctic and the Arctic in the winter. Except in this case it engenders $\mathrm{O}_{3}$ loss over the highly populated central United States in summer.

\section{$1.4 \mathrm{CO}_{2}$ and $\mathrm{CH}_{4}$ release from melting permafrost and methane clathrate}

Compounding the central role that the Arctic plays in setting the time scale for irreversibility regarding the global climate structure, are coupled feedbacks between the increasing temperatures resulting from increased heat flow into the Arctic Basin, and associated carbon release from melting permafrost and methane clathrates. ${ }^{5,6}$ The thinning and loss of the Arctic ice cap, as well as thawing permafrost, tap into the large carbon reservoirs containing both $\mathrm{CH}_{4}$ within clathrates and organic carbon within the terrestrial permafrost system. Methane clathrates are composed of cages of ice structures within which methane, released by the anaerobic decomposition of organic material, is trapped. A key measure of the importance of methane clathrates is reflected in the fact that these clathrates contain an amount of chemical energy two to three times the chemical energy contained in all deposits of petroleum, natural gas, and coal combined worldwide. ${ }^{7}$

As the Arctic Basin melts in response to increasing temperatures, carbon in surface soils will be released as $\mathrm{CH}_{4}$ and $\mathrm{CO}_{2}$ as the depth and geographic range of melt zones increase. For a point of reference, the release of $0.5 \%$ of the labile carbon in the upper 3 meters of the Alaska North Slope and Northern Siberia per annum equals the total carbon released to the

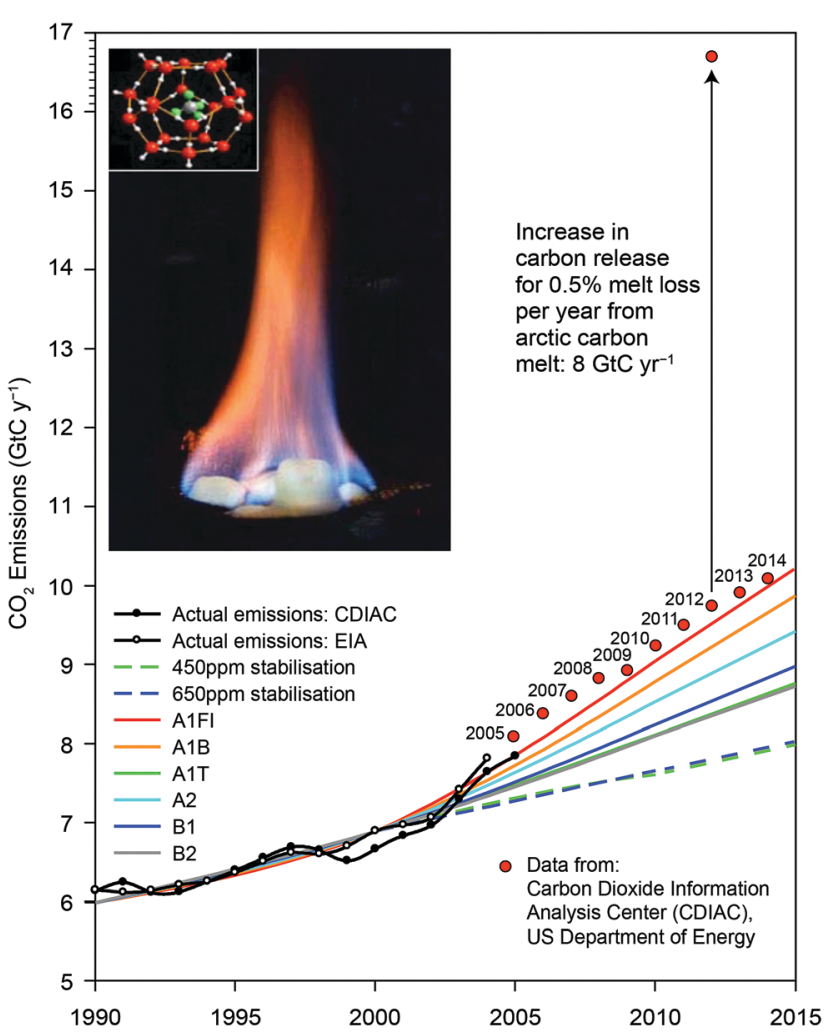

Fig. 4 An important consideration is to compare the fraction of the labile carbon contained in the upper 3 meters of the soils in Northern Siberia and the North Slope of Alaska with that of the total carbon dioxide released worldwide by the extraction, distribution and combustion of fossil fuels. As noted in the figure, just $0.5 \%$ of that labile carbon equals the total mass of carbon added to the atmosphere as $\mathrm{CO}_{2}$ from fossil fuel use.

atmosphere from all fossil fuel extraction, distribution and combustion per annum.

Fig. 4 displays, in the insert, the structure of methane clathrate as well as its combustion. Fig. 4 displays the Intergovernmental Panel on Climate Change (IPCC) analysis tracking the release of carbon added to the atmosphere each year from fossil fuel use for different release scenarios. The actual carbon addition to the atmosphere from fossil fuel use is displayed in the figure since 2007-an amount that exceeds in each year the IPCC projected maximum release rate. ${ }^{8,9}$

A brief examination of the carbon reservoirs in the Arctic reveals the urgency in quantifying carbon fluxes from this region. While the entire human enterprise now contributes ten gigatons of carbon to the atmosphere each year (GtC per year), the Arctic soil reservoir represents between 1400 and $1850 \mathrm{GtC}$ in the upper 3 meters of the soils of the Alaskan North Slope and in Northern Siberia. ${ }^{10,11}$ The reservoirs of methane trapped as gas hydrates are between 30 and $170 \mathrm{Gt}-\mathrm{CH}_{4}$ and between 5 and $195 \mathrm{Gt}^{-\mathrm{CH}_{4}}$ for the Arctic Ocean in Arctic permafrost regions, respectively. If just $0.5 \%$ of the Arctic carbon reservoir is liberated as $\mathrm{CO}_{2}$ and $\mathrm{CH}_{4}$ each year, it will add another $8 \mathrm{Gt}$ to the atmosphere, dramatically adding to the radiative forcing of the climate. The potential for a rapid and irreversible increase in carbon emissions from the Arctic places major importance 
on establishing both the high spatial resolution flux of $\mathrm{CO}_{2}$ and $\mathrm{CH}_{4}$ as well as the mechanism for this release in order to develop tested and trusted forecasts of carbon release in the years and decades ahead. Understanding of carbon release from the Arctic Basin is an imperative.

\subsection{Increased heat flow into the Greenland glacial structure that accelerates sea level rise}

While the Greenland glacial structure has survived intact since the last interglacial period 120000 years ago, the loss of permanent ice in the Arctic has initiated a dramatic change in conditions on Greenland as the time series of satellite observations of surface water ${ }^{12}$ and an analysis of ice mass loss from Greenland ${ }^{13}$ have made clear. Fig. 5, panel A, tracks the formation of summer surface water from 1992 through 2012. Panel B of Fig. 5 highlights the fact that the surface melt water on Greenland flows downward through fissures in the ice structure, breaking the bond between the glacial system and the bedrock. This destabilizes the ice structure and accelerates the decomposition of the glacial system by weakening the horizontal confinement of the ice structure such that it collapses outward and downward. This in turn increases the rate of sea level rise because the reduction in glacial volume results not from the slow melting of a monolithic ice structure, but rather from the collapse of the entire glacial system that can occur far more rapidly than simple melting. Panel C of Fig. 5 represents just one example: the impact on the state of Florida for a 3 meter rise in sea level corresponding to $40 \%$ of the ice volume of Greenland. As the sophistication of the
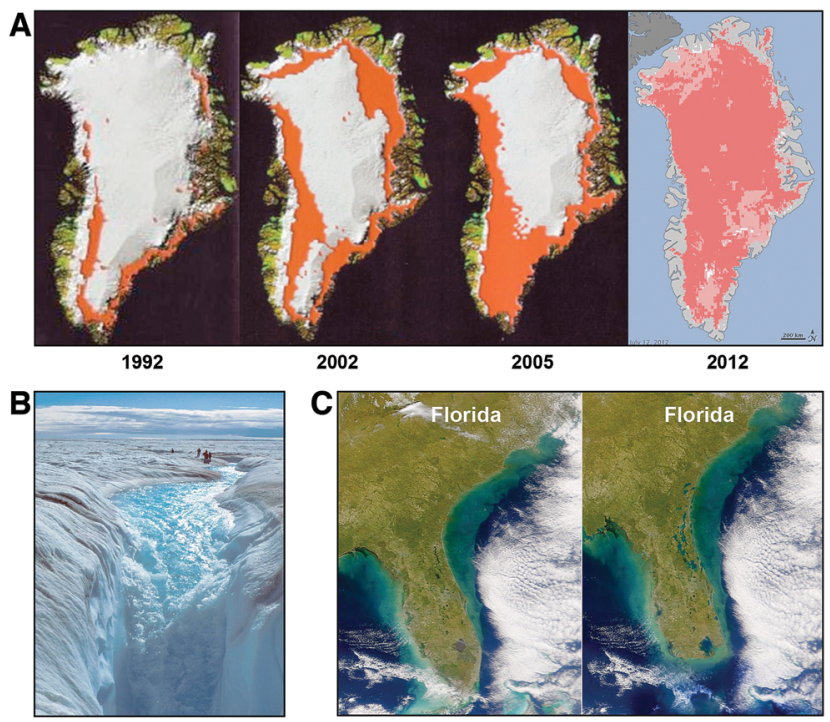

Fig. 5 Satellite observations of the melt water on the surface of the Greenland glacial system is shown in red in panel A tracing the increase in surface water from 1992 to 2012. Prior to the late 1980s, there was no significant surface water on the Greenland glacial system. Panel B shows the down-flow of water from the glacial surface of Greenland that occurs through "moulins" that duct the melt water directly to the bedrock that serves to break the bond between the ice and the bedrock, accelerating the collapse of the ice structure. While Greenland alone contains an ice volume equal to 7 meters of sea level rise, just a 3 meter rise submerges the southern quarter of the state of Florida as displayed in panel $C$. forecast models increases-incorporating improved physics into the glacial dynamics of ice flow and breakup - the amount of sea level rise forecast by the end of the century has increased to between 1.5 and 3 meters, with a probability tail extending to 6 to 7 meters of sea level rise. ${ }^{14,15}$ These forecasts include contributions from the melting of the Antarctic glacial structures that contain an ice volume equal to 70 meters of sea level rise.

\subsection{Coupling increasing levels of $\mathrm{CO}_{2}$ and $\mathrm{CH}_{4}$ to the free radical kinetics controlling ozone loss over the central United States in summer}

As the surface waters of the Gulf of Mexico increase in temperature as a direct response to increasing concentrations of $\mathrm{CO}_{2}$ and $\mathrm{CH}_{4}$ in the atmosphere, exponentially more moisture enters the low-level jet that carries the moisture northward over the central United States where convection is initiated as the river of air ascends over the Great Plains, triggering explosive convection. The resulting severe storms produce convection reaching 6 to 8 kilometers into the stratosphere where the mixture of water and radical precursors from the boundary layer enter the anticyclonic gyre that results from the North American monsoon. This initiation of the flow of warm moist air from the warming surface waters of the Gulf of Mexico is displayed in Fig. 6 along with the anti-cyclonic gyre also displayed in Fig. 6 that serves to capture the convectively injected mixture of water vapor and radical precursors for periods of up to two weeks in July and August, creating a "batch reactor" that allows time for the catalytic removal of ozone to occur. The analysis of the kinetics

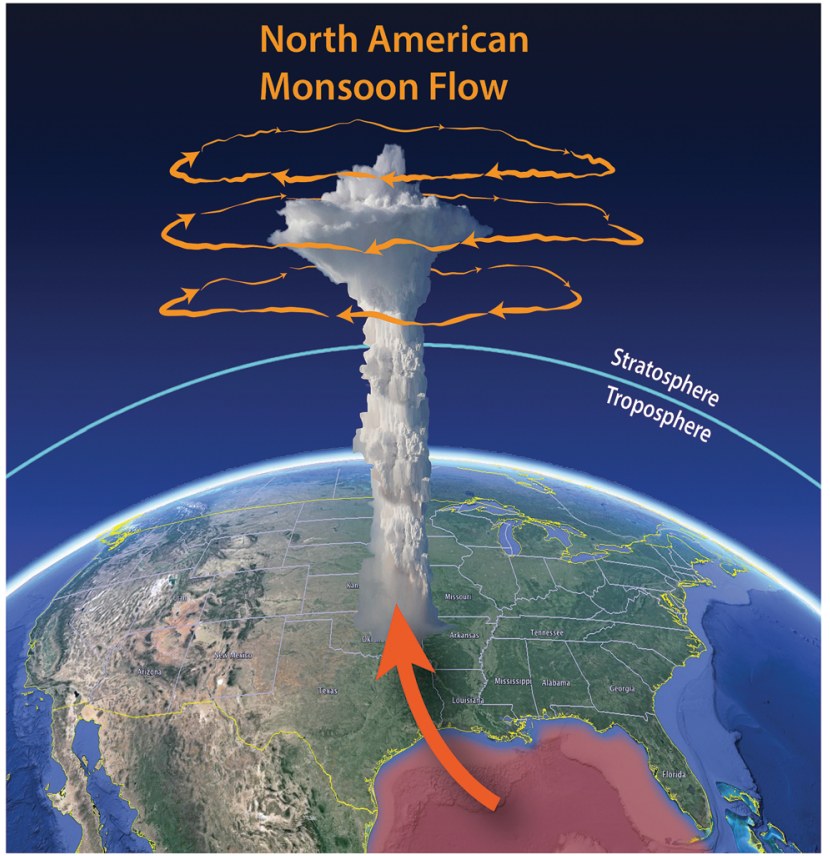

Fig. 6 The warming surface waters of the Gulf of Mexico feed increasing moisture to the low-level jet that delivers water to the central United States in summer, intensifying the convective power of storms that inject water vapor deep into the stratosphere, entering the anti-cyclonic gyre that sequesters the injected mixture of water and radical precursors allowing time for the catalytic loss of ozone. 
of free radical catalyzed loss of stratospheric ozone is treated in the following sections.

\section{Coupling of radical catalyzed loss of stratospheric ozone to climate forcing by increased $\mathrm{CO}_{2}$ and $\mathrm{CH}_{4}$ in the atmosphere}

\subsection{Overview: new observations and mechanistic analysis of catalytic processes}

An array of recent observational evidence ${ }^{4}$ has brought renewed focus on the dynamical and photochemical mechanisms that control ozone in the lower stratosphere over the United States in summer. In particular, the coupling of six factors, when considered in specific combinations, define why the central US in summer represents a unique case, in the global context, of the risk of regional ozone loss. These factors, depicted in Fig. 7, include:

(1) Warming surface waters of the Gulf of Mexico that induce increased water vapor carried by the low-level jet that feeds warm, moist air to the lower atmosphere over the central United States inducing in turn;

(2) development of severe storm systems over the Great Plains of the US with convective cores that extend well above the tropopause, leading to the injection of water vapor and possibly halogen radical precursors deep into the stratosphere $;{ }^{16-19}$

(3) anti-cyclonic flow in the stratosphere over the US in summer, associated with the North American monsoon (NAM), that serves to increase the retention time of the convectively injected species over the US ${ }^{20,21}$ creating in effect a photochemical batch reactor;

(4) increased probability for the catalytic conversion of inorganic chlorine (primarily $\mathrm{HCl}$ and $\mathrm{ClONO}_{2}$ - hereafter $\mathrm{Cl}_{\mathrm{y}}$ ) to free radical form (ClO) on ubiquitous sulfate aerosols due to a combination of gravity wave induced ambient temperature perturbations and localized water vapor enhancements, which can accelerate the catalytic removal of ozone in the lower stratosphere; ${ }^{17,22}$

(5) potential for future sulfate enhancements from volcanic eruptions $^{23-26}$ or overt addition by the geoengineering approach of reducing solar forcing by increasing albedo via solar radiation management (SRM); ${ }^{27-32}$

(6) and increased forcing of the climate by continued $\mathrm{CO}_{2}$ and $\mathrm{CH}_{4}$ emissions from the extraction, transport and combustion of fossil fuels, that has the potential to increase the frequency and intensity of storm systems over the Great Plains in summer. ${ }^{33-36}$

In this section we present observations that define:

(a) the frequency and depth of convective penetration into the stratosphere of condensed phase water over the central US in summer employing the NEXRAD weather radar system,

(b) available inorganic chlorine placed within the same vertical coordinate system as the NEXRAD observations,

(c) high accuracy, high spatial resolution in situ observations of the temperature structure of the lower stratosphere over the

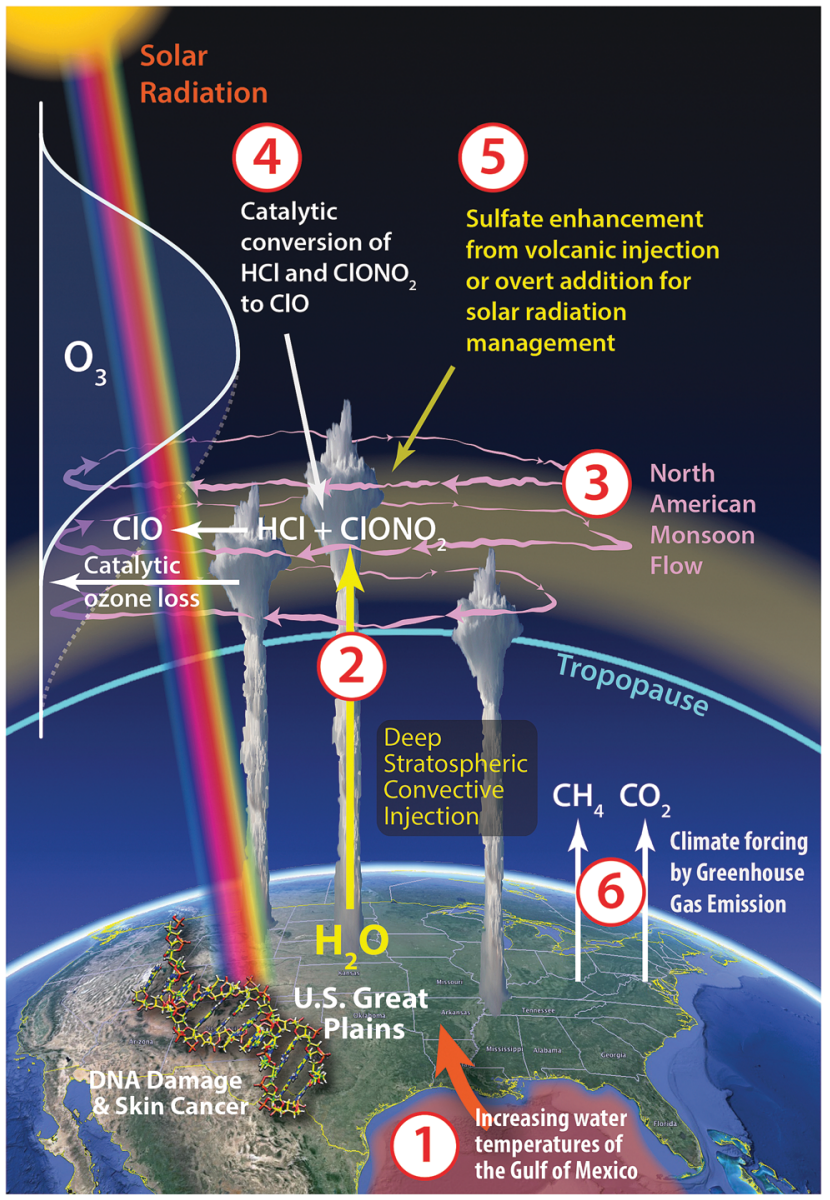

Fig. 7 In the context of climate-chemistry coupling globally, the central US in summer represents a combination of factors specific to both the geographic region and the season. Northerly flow of warm moist air from the Gulf of Mexico in combination with heating and convergence over the Great Plains frequently triggers powerful convection that injects water vapor into the stratosphere, where the upper level anti-cyclonic flow associated with the NA monsoon can sequester the injection for a week or more over the US. This, in combination with cold stratospheric temperatures, can lead to heterogeneous catalysis on ubiquitous sulfate-water aerosols that converts inorganic chlorine to $\mathrm{ClO}$ and can initiate ozone loss through an array of gas-phase catalytic cycles. Potential future enhancements in sulfate from volcanic injection or geoengineering increase the likelihood of halogen activation and ozone loss.

US in summer that clarify the importance of spatial and structural variability and gravity wave propagation on the heterogeneous catalytic conversion of inorganic chlorine to free radical form, and

(d) to use the observations of convective penetration heights, elevated water vapor, and temperatures as inputs to a photochemical model, ${ }^{24,37-39}$ which calculates concentrations of the rate limiting $\mathrm{ClO}, \mathrm{BrO}, \mathrm{HO}_{2}$ and $\mathrm{NO}_{2}$ radicals that control the catalytic loss rate of ozone and the resulting fractional decrease in ozone.

The context for the analysis presented here concerns the issue of human health associated with the remarkable sensitivity of humans to small increases in UV dosage that initiate skin cancer. In particular, diagnosed cases of basal cell and 
squamous cell carcinoma have reached 3.5 million annually in the US alone. ${ }^{40-43}$ The analysis presented here of the sensitivity of lower stratospheric ozone over the US in summer builds on four decades of developments linking chlorine and bromine radicals to ozone loss in the polar regions, ${ }^{44,45,55}$ and to ozone depletion at mid-latitudes resulting from the coupling of volcanic aerosols and temperature variability to anthropogenic chlorine and bromine, ${ }^{22,24,25,56}$ as well as analyses of the consequences from sulfate addition to the stratosphere from geoengineering via solar radiation management. ${ }^{29-32}$ Finally, while detailed simultaneous observations of the key catalytic free radicals, reactive intermediates and ozone loss rates have been thoroughly investigated in the stratosphere over the Antarctic and Arctic in winter, the same is not the case for the stratosphere over the US in summer.

\subsection{Photochemical framework for catalytic ozone loss in the lower stratosphere}

Studies of catalytic ozone loss in the lower stratosphere at high latitudes established the network of catalytic reactions linking inorganic chlorine to the rate of ozone loss in the lower stratosphere. Simultaneous in situ aircraft observations of $\mathrm{ClO}, \mathrm{BrO}$, ClOOCl, $\mathrm{ClONO}_{2}, \mathrm{HCl}, \mathrm{OH}, \mathrm{HO}_{2}, \mathrm{NO}_{2}$, particle surface area, $\mathrm{H}_{2} \mathrm{O}$ and $\mathrm{O}_{3}$ in the transition through the boundary of the Arctic vortex $^{49-52}$ showed explicitly the loss of ozone as well as the distinct anti-correlation between the concentration of the rate limiting radical $\mathrm{ClO}$ and the ozone concentration. It is the chlorine monoxide radical, $\mathrm{ClO}$, in combination with the rate limiting step (RLS) $\mathrm{ClO}+\mathrm{ClO}+\mathrm{M} \rightarrow \mathrm{ClOOCl}+\mathrm{M}$ in the catalytic cycle first introduced by Molina and Molina ${ }^{46}$ and the catalytic cycle rate limited by $\mathrm{ClO}+\mathrm{BrO} \rightarrow \mathrm{Cl}+\mathrm{Br}+\mathrm{O}_{2}$ first introduced by McElroy et al. ${ }^{47}$ that constitute the reaction mechanisms capable of removing ozone over the polar regions in winter at the observed rates. ${ }^{48,53,54}$

A distinguishing feature of the regime within the polar jet, which defines the boundary of the Arctic vortex in winter, is that temperatures within the vortex are lower by approximately 6-7 $\mathrm{K}$ than outside the vortex. This modest suppression in temperature is adequate to trigger the heterogeneous catalytic conversion of $\mathrm{Cl}_{\mathrm{y}}$ to $\mathrm{Cl}_{2}$ and $\mathrm{HOCl}$ at $\mathrm{H}_{2} \mathrm{O}$ mixing ratios of 4.5 ppmv on simple, ubiquitous sulfate aerosols. ${ }^{22,57-60} \mathrm{The}^{\mathrm{Cl}_{2}}$ and $\mathrm{HOCl}$ products of $\mathrm{Cl}_{\mathrm{y}}$ heterogeneous catalysis on sulfate aerosols ${ }^{45}$ photodissociate to produce $\mathrm{Cl}$ atoms that react with $\mathrm{O}_{3}$ to produce ClO. Hereafter, we refer to this series of reactions as the conversion of $\mathrm{Cl}_{\mathrm{y}}$ to $\mathrm{ClO}$.

Examination of conditions in the Arctic lower stratosphere coupled with extensive results from laboratory experiments and modeling ${ }^{57-60}$ have set in place the temperature-water vaporsulfate coordinate system defining the regime of rapid heterogeneous conversion of $\mathrm{Cl}_{\mathrm{y}}$ to ClO. ${ }^{57}$ Fig. 8 displays a schematic illustrating the temperature-water vapor threshold between the domain in which conversion of inorganic chlorine to its catalytically active forms becomes significant (shaded region) and the temperature-water vapor domain that leaves inorganic chlorine bound in its reservoir species (unshaded region). ${ }^{57-60}$ Probabilities $(\gamma$ 's) associated with the heterogeneous reactions considered here

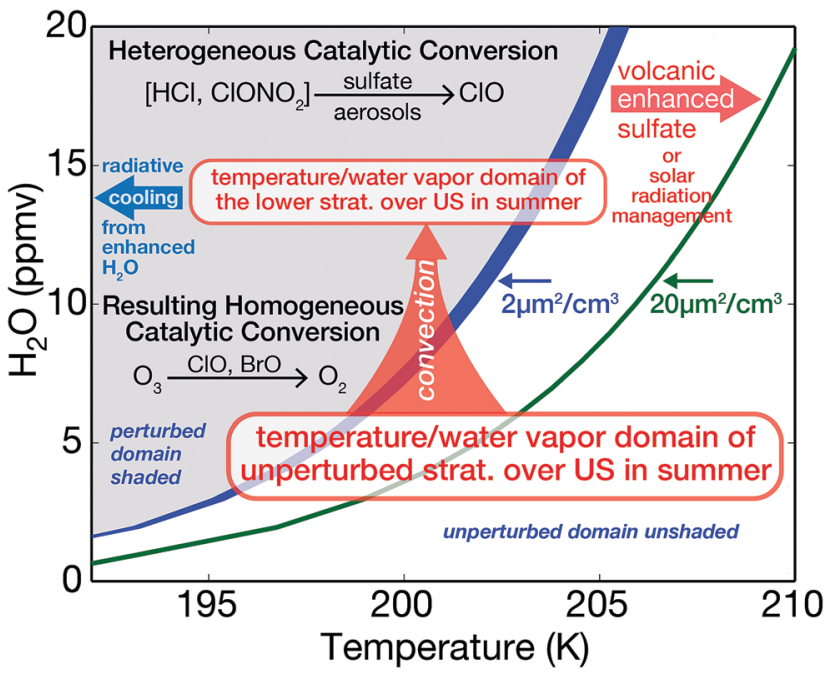

Fig. 8 An example of the three-dimensional dependence of heterogeneous catalytic conversion of inorganic chlorine $\left(\mathrm{Cl}_{y} \approx \mathrm{HCl}+\mathrm{ClONO}_{2}\right)$ on temperature, water vapor and sulfate loading is displayed in a manner that distinguishes rapid conversion of $\mathrm{Cl}_{y}$ to free radical form in the shaded region (with the threshold defined as 10\% chlorine activation in the first diurnal period) from the unshaded region for which there is virtually no $\mathrm{Cl}_{y}$ to $\mathrm{ClO}$ conversion. This establishes the photochemical framework for the analysis of convective addition of water, sulfate addition by volcanic injection or overt sulfate addition for solar radiation management (SRM), or combinations thereof. The broad blue line dividing the perturbed and unperturbed domains corresponds to a sulfate reactive surface area of $2 \mu \mathrm{m}^{2} \mathrm{~cm}^{-3}$; the green line represents a shift in sulfate reactive surface area to $20 \mu \mathrm{m}^{2} \mathrm{~cm}^{-3}$.

are sensitive to aerosol composition. ${ }^{57-60}$ In particular, reactions involving $\mathrm{HCl}$ are governed by its uptake and solubility, which are strongly dependent on both the sulfuric acid weight percent of the aerosol and temperature. As the sulfuric acid weight percent decreases, the solubility of $\mathrm{HCl}$ increases. The sulfuric acid weight percent is itself a function of relative humidity. With shifts to colder temperatures and/or higher water vapor mixing ratios leading to more dilute sulfate within the aerosol, the reaction probabilities for the conversion of $\mathrm{Cl}_{\mathrm{y}}$ to $\mathrm{ClO}$ increase exponentially. Therefore, wherever the specific conditions of temperature and water vapor are satisfied, the heterogeneous catalytic conversion of $\mathrm{Cl}_{\mathrm{y}}$ to $\mathrm{ClO}$ can occur on the simple, ubiquitous binary aerosol, and ozone loss can result.

The cornerstone of our understanding of sulfate-halogen induced reductions in ozone over mid-latitudes of the northern hemisphere $(\mathrm{NH})$ is built upon observed column ozone loss following the 1991 eruption of Mt. Pinatubo. ${ }^{22,24-26}$ The impact of the volcanic eruption on ozone extended over a period of nearly four years following the eruption when column ozone concentrations over the $\mathrm{NH}$ decreased by a maximum of $5 \%$ in the latitude region $35-60^{\circ} \mathrm{N} .{ }^{24}$ Model analysis of the impact emphasized the central role of halogen radical catalytic loss of ozone, particularly the important role of bromine radicals in the lower stratosphere at elevated levels of sulfate aerosol loading. ${ }^{24}$ The addition of sulfate to the stratosphere by either volcanic injection or overt addition for SRM is indicated in Fig. 8 as the sulfate "shift" to the green line that serves to expand the domain 
for rapid heterogeneous catalytic conversion of $\mathrm{Cl}_{\mathrm{y}}$ to $\mathrm{ClO}$. Radiative cooling to space from the domain of enhanced water vapor is displayed with the blue arrow in Fig. 8 .

The four catalytic cycles that must be taken into account in the assessment of ozone loss rates in the lower stratosphere include the most important rate limiting steps under unperturbed as well as perturbed conditions, i.e., conditions of elevated water vapor or lower temperatures. In this analysis "unperturbed" refers to background sulfate loading of $1-3 \mu \mathrm{m}^{2} \mathrm{~cm}^{-3}$ and a water vapor mixing ratio of $4.5 \mathrm{ppmv}$. The four dominant rate limiting catalytic steps include: (1) $\mathrm{ClO}+\mathrm{ClO}+\mathrm{M} \rightarrow \mathrm{ClOOCl}+\mathrm{M}$, (2) $\mathrm{BrO}+\mathrm{ClO} \rightarrow \mathrm{Br}+\mathrm{Cl}+\mathrm{O}_{2}$, (3) $\mathrm{NO}_{2}+\mathrm{O} \rightarrow \mathrm{NO}+\mathrm{O}_{2}$ and (4) $\mathrm{HO}_{2}+\mathrm{O}_{3} \rightarrow \mathrm{OH}+2 \mathrm{O}_{2}$. Under unperturbed conditions in the lower stratosphere between 10 and $22 \mathrm{~km}$, the catalytic loss of ozone is dominated by the $\mathrm{HO}_{2}+\mathrm{O}_{3} \rightarrow \mathrm{OH}+2 \mathrm{O}_{2} \mathrm{RLS}$, as originally demonstrated by Wennberg et al. ${ }^{61}$ The $\mathrm{ClO}+\mathrm{BrO}$ cycle plays a significant role $(\sim 15 \%)$, exceeding the ClO dimer catalytic cycle by more than an order of magnitude under unperturbed conditions. Above approximately $22 \mathrm{~km}$, the catalytic cycle rate limited by $\mathrm{NO}_{2}+\mathrm{O} \rightarrow \mathrm{NO}+\mathrm{O}_{2}$ becomes dominant. The rate limiting catalytic species $\mathrm{ClO}, \mathrm{BrO}, \mathrm{HO}_{2}$ and $\mathrm{NO}_{2}$ thus constitute the baseline against which unperturbed conditions may be contrasted relative to perturbed cases involving temperature variability and the convective injection of water vapor.

\subsection{NEXRAD weather radar map of storm-top height geographic distribution and penetration depth into the stratosphere over the US in summer}

The Next-Generation Radar (NEXRAD) weather radar network has markedly advanced our understanding of both the frequency and depth of tropopause-penetrating convection in the lower stratosphere over the US in summer. Prior to the radar analysis methods applied by Solomon et $a .^{62}$ for mapping the $3 \mathrm{D}$ structure of convective penetration, elevated water vapor mixing ratios in the stratosphere were observed in situ during multiple summertime aircraft missions over the US. ${ }^{16,17,63}$ These observations of both vapor phase $\mathrm{H}_{2} \mathrm{O}$ and the HDO isotopologue, obtained aboard NASA's WB-57 and ER-2 aircraft, provide direct evidence of water vapor deposited by convection in the stratosphere. Maximum water vapor values observed in situ range from 8 to 18 ppmv for individual plumes typically sampled a day to a few days after convective injection. In support of the in situ observations, the NEXRAD weather radar data provide compelling statistics on the frequency, 3D structure, and high accuracy determination of the storm-top altitude of convection.

Solomon et $a .^{62}$ used radar analysis methods and observations from the operational NEXRAD radar network to create a high-resolution, three-dimensional, gridded radar reflectivity product for 2004 over the conterminous US east of the Rocky Mountains. By combining the NEXRAD analysis with the lapserate tropopause height derived from the European Center for Medium-Range Weather Forecasting ERA-Interim reanalysis, they produced high-resolution maps of convection overshooting the tropopause level at 3 hour intervals for the entire year. The ERA-Interim estimates of the tropopause altitude agree well with high vertical resolution observations from radiosondes. ${ }^{64}$
These ice-rich overshooting parcels lead to injection of water vapor into the stratosphere through mechanisms including turbulent mixing and gravity wave breaking. ${ }^{64}$

The geographic distribution of overshooting events is markedly non-uniform, with the great majority occurring east of the Rocky Mountains and west of the Mississippi River. The largest concentration of overshooting events occurs over the high plains stretching from Texas to Nebraska and Iowa. The ongoing analysis of a 10-year hourly NEXRAD dataset for May through August of 2004 to 2013 confirms the diurnal, annual, and geographical patterns found by Solomon et al. ${ }^{62}$ A key contribution that the NEXRAD system provides is the ability to map the stormtop potential temperature as a function of geographic position, frequency and month of occurrence. The multi-year analysis indicates that 38158 storms reached at least $2 \mathrm{~km}$ above the tropopause over the central US in May-August between 2004 and 2013 , with about $50 \%$ of these extending above the $390 \mathrm{~K}$ potential temperature level (approximately $16 \mathrm{~km}$ ). The depth and frequency of penetration has significant consequences, so we delineate here the quantitative specifics of the NEXRAD observations with high spatial resolution values of $\mathrm{HCl}$ that inform the altitudedependent distribution of available inorganic chlorine.

The vertical coordinate system most appropriate for the quantitative coupling of the NEXRAD observations to that of inorganic chlorine is potential temperature (the temperature of an air parcel compressed adiabatically to $1000 \mathrm{hPa}$ ) because, in the absence of diabatic processes, air parcels in the stratosphere are transported along surfaces of constant potential temperature, such that long-lived trace species exhibit consistent correlations with one another. In particular, this is a characteristic shared by long-lived tracers that are either produced or removed by increasing UV radiation as a function of increasing altitude in the stratosphere, e.g., $\mathrm{HCl} v s . \mathrm{O}_{3}$ and $\mathrm{Cl}_{\mathrm{y}}$ vs. $\mathrm{N}_{2} \mathrm{O}$. Data from multiple in situ measurement campaigns, as well as satellite retrievals, have been used to quantify the relationships among these species. ${ }^{54,65}$ In Fig. 9, high resolution vertical profiles of $\mathrm{HCl}$ mixing ratio (blue data points) were inferred from in situ measurements of $\mathrm{O}_{3}$ using the linear relationship between Aura Microwave Limb Sounder (MLS) measurements of $\mathrm{HCl}$ and $\mathrm{O}_{3}$ at $100 \mathrm{hPa}$ and $68 \mathrm{hPa}$, such that $\mathrm{HCl}(\mathrm{pptv}) \approx 7.0 \times 10^{-4} \times \mathrm{O}_{3}$ (pptv). MLS version 4.2 data from 2004-2016, sub-selected to be between $30^{\circ}-50^{\circ} \mathrm{N}$ and $80^{\circ}-105^{\circ} \mathrm{W}$ for June through August, were used to derive this conversion factor. The in situ $\mathrm{O}_{3}$ data used to calculate $\mathrm{HCl}$ throughout the lower stratosphere over the US in summer are from the NASA Studies of Emissions and Atmospheric Composition, Clouds, and Climate Coupling by Regional Surveys (SEAC ${ }^{4} \mathrm{RS}$ ) mission, which took place over the US in the summer of 2013. Shown in Fig. 9 are in situ measurements of $\mathrm{HCl}$ from the NASA AVE campaign over the US in June 2005 as the array of black data points. $\mathrm{HCl}$ comprises most of the inorganic chlorine in the lower stratosphere, and accordingly, Fig. 9 demonstrates the rapid rise in available inorganic chlorine with increasing potential temperature (altitude).

In order to appraise the quantitative impact on ozone catalytic loss rates of variations in both temperature and convectively 


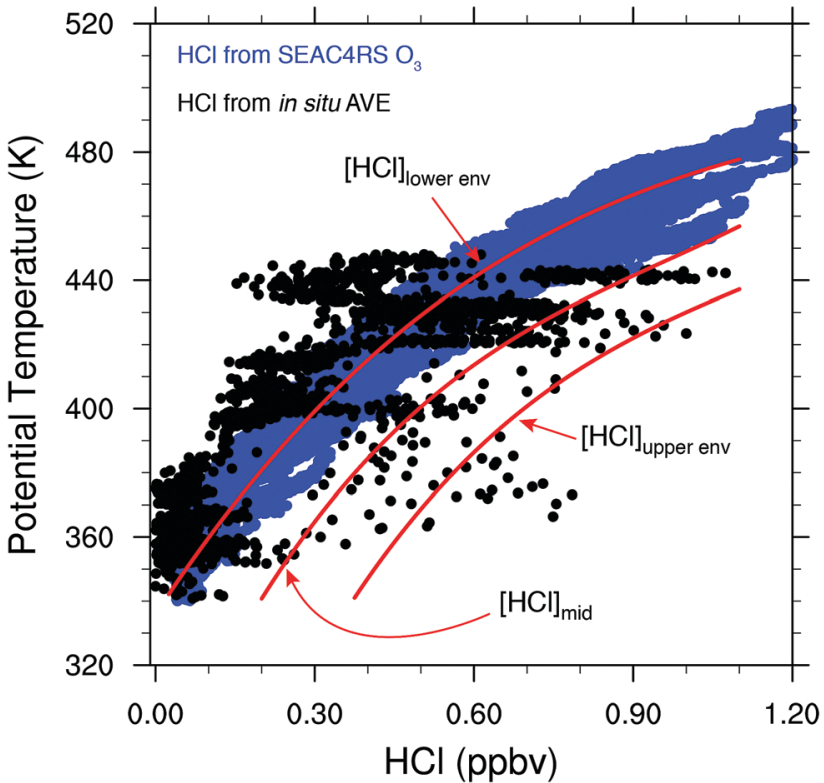

Fig. 9 The profile of $\mathrm{HCl}$ mixing ratio with height is displayed where the nested blue points trace out $\mathrm{HCl}$ calculated using in situ $\mathrm{O}_{3}$ data from the NASA SEAC ${ }^{4} R S$ mission (see text). The black points are in situ observations obtained with the Chemical Ionization Mass Spectrometer (CMIS) instrument during the NASA Aura Validation Experiment (AVE) mission in June of 2005. Data acquired between $30^{\circ}$ and $50^{\circ} \mathrm{N}$ latitude and $80^{\circ}$ and $110^{\circ} \mathrm{W}$ are displayed. The curved red lines represent the three ranges of $\mathrm{HCl}$ : $[\mathrm{HCl}]_{\text {lower env, }}[\mathrm{HCl}]_{\text {mid, }}$ and $[\mathrm{HCl}]_{\text {upper env }}$ used in the calculations of ozone loss.

injected water vapor, three profiles of the $\mathrm{HCl}$ mixing ratio are chosen to represent the range in observed $\mathrm{HCl}$ : $[\mathrm{HCl}]_{\text {lower env }}$ and $[\mathrm{HCl}]_{\text {upper env }}$ that represents the lower and upper bound of $\mathrm{HCl}$ in situ observations, and $[\mathrm{HCl}]_{\text {mid }}$ that represents the midpoint of $\mathrm{HCl}$ in situ observations.

Subsequent to the high in situ water vapor observations reported by Anderson et al., ${ }^{3,4}$ Schwartz et al. ${ }^{66}$ analyzed satellite observations of water vapor from MLS and confirmed that the lower stratosphere over the United States in summer is indeed unusually wet, with measured values reaching as high as 18 ppmv. The MLS satellite data indicate that the highest stratospheric water vapor mixing ratios at the highest latitudes globally are over the central and eastern US in summer. These results are particularly noteworthy, because the true magnitude and number of water vapor enhancements over the US in summer is likely significantly greater than reported by the MLS satellite instrument. The reason is that elevated $\mathrm{H}_{2} \mathrm{O}$ from convective injection is localized in space and typically layered vertically, such that the spatial resolution of MLS (e.g., $3 \mathrm{~km}$ vertical $\times 200 \mathrm{~km}$ horizontal at $100 \mathrm{mb}$ for $\mathrm{H}_{2} \mathrm{O}$ ) may often exceed the dimensions of the perturbation or randomly transect it, leading to an underestimate of the mixing ratio. For example, a $2 \mathrm{~km}$ deep layer of elevated water of $50 \mathrm{~km}$ horizontal extent, even with optimal alignment of the convected geometry along the north-south viewing track of MLS, will only fill 1/6 of the MLS sample volume with the other $5 / 6$ filled with background levels of $\mathrm{H}_{2} \mathrm{O}$. This results in a substantial underreporting of the actual $\mathrm{H}_{2} \mathrm{O}$ mixing ratio present within the convected domain. Nevertheless, Schwartz et al. ${ }^{66}$ established the crucial fact that the stratosphere over the central and eastern US is unique globally with respect to significantly elevated water vapor.

Another key piece of evidence relating the observations of enhanced water vapor to their convective source comes from the ACE-FTS satellite observations of the concentration of the heavy water isotopologue HDO globally in the lower stratosphere ${ }^{67}$ as well as in situ observations of HDO within regions of convective injection from NASA aircraft missions. The $\mathrm{HDO}$ to $\mathrm{H}_{2} \mathrm{O}$ ratio is expressed in the usual isotopic formulation of $\delta D$ that is reported in per-mil units and defined as $\delta D(\%)=\left(R_{\mathrm{obs}} / R_{\mathrm{SMOW}}-1\right) \times 1000$ where $R=[\mathrm{HDO}] /\left[\mathrm{H}_{2} \mathrm{O}\right]$, "SMOW" refers to standard mean ocean water, and $R_{\text {SMOW }}=3.12 \times 10^{-4}$. Observations of $\delta D$ are important because convective injection followed by sublimation is characterized by less negative values of $\delta D$ in water vapor compared to air that has passed through the tropical tropopause, which has $\delta D$ values of around $-650 \%$. This corresponds to a $65 \%$ depletion of HDO relative to standard mean ocean water. In situ aircraft measurements of convective outflow show $\delta D$ values of $-200 \%{ }^{68}$ The ACE-FTS global observations of $\delta D$ at $16.5 \mathrm{~km}$ from Randel et al. ${ }^{67}$ show $\delta D$ values of $\sim-490 \%$ over North America but virtually no enhancement of $\delta D$ over the global mean at $16.5 \mathrm{~km}$ altitude in any other geographic domain, including the Asian monsoon region. This is direct evidence for the convective source of water vapor in the stratosphere over the US in summer as well as for the unique occurrence of deep stratosphere-penetrating convection in the global context.

\subsection{Observations of temperatures in the lower stratosphere} over the US in summer

We employ high spatial resolution, high accuracy in situ temperature measurements acquired in the specific altitude, latitude, longitude and season appropriate for calculations of localized ozone loss in the lower stratosphere over the central US in summer. ${ }^{4}$ These temperature data were acquired aboard the NASA ER-2 high altitude aircraft on flights in the stratosphere during August and September 2013 over the central US during the NASA SEAC ${ }^{4}$ RS mission. For the present analysis, which focuses specifically on the central US east of the Rocky Mountains, we select temperature data in the latitude range from $30^{\circ}$ to $50^{\circ} \mathrm{N}$ and in longitude from $110^{\circ}$ to $80^{\circ} \mathrm{W}$. Three temperature curves, shown in Fig. 10, were selected to illustrate the extreme sensitivity to colder temperatures of the catalytic mechanisms that determine the rate of ozone loss under perturbed conditions. The three temperatures that we consider are:

- $T_{\text {std }}$ that represents a standard temperature typically employed in stratospheric modeling,

- $T_{\text {avg }}$ that is the actual observed average temperature obtained from the in situ aircraft observations over the central United States in summer, calculated by averaging the data over $10 \mathrm{~K}$ potential temperature bins centered on the isentropic level of interest, and

- $T_{\text {env }}$ that is the envelope of temperatures observed in situ by the aircraft that traces the observed temperature excursions 




Fig. 10 Three temperature profiles are used in the calculations of ozone catalytic loss. The temperature distribution $T_{\text {std }}$ displayed in black is a standard temperature typically used in 2D and 3D models, $T_{\text {avg }}$ is the average of the observed temperatures obtained by high accuracy in situ aircraft measurements over the central United States in summer, and $T_{\text {env }}$ is the envelope of aircraft observed in situ temperature observations that reflect the amplitude of the temperature oscillation resulting from the propagation of gravity waves through the stratosphere. The period of oscillation of the temperature for a single gravity wave is on average 6 to 7 hours. The period of time for the heterogeneous catalytic conversion of $\mathrm{HCl}$ to $\mathrm{ClO}$ is on the order of a few hours, so the constant series of gravity waves traversing the stratosphere place particular importance on the envelope temperature $T_{\text {env }}$ in the analysis of the kinetics of ozone catalytic loss in the stratosphere over the US in summer.

resulting from the propagation of gravity waves through the stratosphere.

Because the catalytic conversion of $\mathrm{HCl}$ and $\mathrm{ClONO}_{2}\left(\right.$ i.e. $\left.\mathrm{Cl}_{\mathrm{y}}\right)$ to ClO occurs in a matter of a few hours under perturbed conditions of convectively injected water vapor, combined with the fact that the average period of the gravity wave oscillation is in the range 6 to 7 hours, the $T_{\text {env }}$ temperature is the most important for the analysis of the heterogeneous catalytic chemistry converting Cly to ClO. The central objective in the analysis of the temperature dependence of the catalytic chemistry is to demonstrate the extreme sensitivity to temperature within the range of the observed temperatures. The observed temperatures from the aircraft in situ measurements are displayed as the gray dots in Fig. 10.

In the following modeling analysis, the three different temperature profiles, $T_{\text {std }}, T_{\text {avg }}$, and $T_{\text {env }}$, are employed to evaluate the response of the rate limiting steps for the catalytic loss of stratospheric ozone to (a) temperature alone in the absence of enhanced convectively increased water vapor, (b) the amount of convectively injected water vapor expressed in terms of the mixing ratio of water vapor, and (c) the amount of $\mathrm{HCl}$ present in the atmosphere prior to convective injection of water vapor. The amount of $\mathrm{HCl}$ present in the stratosphere over the central United States is seasonally dependent as $\mathrm{HCl}$ is enhanced by the equatorward flow from high latitudes following the breakup of the Arctic vortex. The diabatic cooling within the Arctic vortex during winter brings the $\mathrm{HCl}$ rich air to lower altitudes.

Fig. 10 defines the range in observed temperatures in the lower stratosphere over the central US in summer. Spatial and structural variability in combination with gravity waves that continuously traverse the lower stratosphere over the Great Plains in summer contribute to the observed temperature variability. These gravity waves are induced by strong convective events embedded in mesoscale convective systems (MCSs), squall lines and tornadic storm structures, as well as the presence of the Rocky Mountains. ${ }^{69}$ Also potentially contributing to the temperatures in the domain of elevated water vapor from convective injection is the radiative cooling of the region of enhanced water vapor to space at a rate of $\sim 0.5 \mathrm{~K}$ per day per $10 \mathrm{ppmv}$ of additional water vapor. ${ }^{70,71}$ Given the remarkable non-linearity of the heterogeneous catalytic processes that control $\mathrm{HCl}$ to $\mathrm{ClO}$ conversion, the temperature observations are critically important for the determination the rate of catalytic loss of ozone.

\subsection{Dynamics defining lower stratospheric flow patterns over the US in summer}

The North American monsoon creates a situation during July and August that is particularly conducive to the hydration of the lower stratosphere by extremely deep convection. Not only does it steer water vapor from the Gulf of Mexico across Texas and into the western Plains States in the lower atmosphere, it also generates an anticyclone in the upper troposphere and lower stratosphere that causes stratospheric air parcels to dwell markedly longer over North America than if they were advected by a purely zonal flow. This anticyclonic circulation is not stable, though, leading to regular ventilation. Thus the mean residence time of air over the US ranges from one to two weeks with some parcels residing significantly longer. ${ }^{72}$ This sets the range of timescales for evaluating ozone loss over this region from one or more of these injections. Evidence that parcels are induced to circulate in a stratospheric anticyclone over North America during summer with convectively injected water vapor retention within the gyre is evident in tracer-tracer ${ }^{21}$ and satellite data. ${ }^{73-75}$ It is important to note that while the heterogeneous catalytic conversion of $\mathrm{Cl}_{\mathrm{y}}$ to $\mathrm{ClO}$ on sulfate-water aerosols takes but a few hours following convective injection, the subsequent homogeneous catalytic loss of ozone takes place in the subsequent days and weeks following convective injection.

\subsection{Model calculations exploring the sensitivity of the rate limiting steps in the dominant ozone loss processes to perturbations in temperature and water vapor}

Given the remarkable temperature sensitivity and non-linearity of the heterogeneous catalytic conversion of $\mathrm{Cl}_{\mathrm{y}}$ to $\mathrm{ClO}$ on sulfate aerosols, and the sensitivity of ozone loss rates to changes in the concentrations of the rate limiting radicals $\mathrm{ClO}, \mathrm{BrO}, \mathrm{HO}_{2}$, and $\mathrm{NO}_{2}$, we model the stratospheric ozone system over the central 
US with a one dimensional chemical kinetics model used to simulate the conditions at various isentropic (constant potential temperature) levels for a stratospheric background condition derived from a regional and seasonal average. The range of potential temperatures considered extends from $340 \mathrm{~K}$ to $430 \mathrm{~K}$ (approximately 12 to $18 \mathrm{~km}$ ). Background stratospheric concentration potential temperature profiles of relevant chemical species were obtained from a decadal and regional average of Aura-MLS satellite data in the summer months (June, July and August) of 2004 to 2013 in the central US defined as $30^{\circ} \mathrm{N}$ to $50^{\circ} \mathrm{N}$ and $110^{\circ}$ to $80^{\circ} \mathrm{W}$ for $\mathrm{HNO}_{3}, \mathrm{H}_{2} \mathrm{O}$, and $\mathrm{O}_{3}$. Background profiles for $\mathrm{NO}_{2}$, NO and inorganic bromine were obtained from in situ observations. Each background chemical profile was interpolated to the model potential temperature surfaces. The chemical model tracks 32 chemical species and 67 reactions. Most important of these reactions are the free radical cycles that destroy stratospheric ozone: the $\mathrm{HO}_{x}, \mathrm{NO}_{x}$ and $\mathrm{ClO}_{x}$ cycles. Of particular importance are the initiation reactions of the $\mathrm{ClO}_{x}$ cycle and the heterogeneous activation of inorganic chlorine, due to their sensitivity to both water vapor concentration and temperature. The model state is defined by the chemical species concentrations and is integrated forward in time using the LSODA ordinary differential equation (ODE) solver. The LSODA program was selected for its ability to utilize both stiff (backward differentiation formula) and non-stiff (Adams) methods. An adaptive time step was also implemented over the integration period. Each potential temperature level was simulated independently for a time period of two weeks using three different temperature profiles and water vapor concentrations of 5 ppmv (stratospheric background), 10 ppmv and 20 ppmv (convectively influenced).

2.6.1 Response of catalytic ozone loss to temperature. Fig. 11 displays the loss rate of ozone for each of the major catalytic cycles rate limited by $\mathrm{ClO}+\mathrm{ClO}, \mathrm{ClO}+\mathrm{BrO}, \mathrm{NO}_{2}+\mathrm{O}$, and $\mathrm{HO}_{2}+\mathrm{O}_{3}$ for each of the three temperature profiles $T_{\text {std }}$, $T_{\text {avg }}$, and $T_{\text {env }}$ between 12 and $20 \mathrm{~km}$ employing an $\mathrm{HCl}$ concentration profile corresponding to $[\mathrm{HCl}]_{\text {mid }}$ in Fig. 9. Fig. 11 clarifies the important role that the temperature structure plays in ozone catalytic chemistry. Calculations of ozone loss rates using $T_{\text {std }}$ establish the baseline case against which ozone loss for the observed temperature distribution, displayed previously in Fig. 10, can be contrasted. Calculations using the observed $T_{\text {avg }}$ result in marginally modified but similar loss rates for all four major catalytic cycles when compared with the case for $T_{\mathrm{std}}$. However, for the very modest decrease in temperature represented by the difference between the observed $T_{\text {avg }}$ and observed $T_{\text {env }}$ in Fig. 10, the response of the catalytic cycles is marked. The $\mathrm{ClO}+\mathrm{ClO}$ loss rate increases by more than five orders of magnitude in the altitude region between 12 and $16 \mathrm{~km}$, and the $\mathrm{ClO}+\mathrm{BrO}$ loss rate increases by more than two orders of magnitude. The $\mathrm{NO}_{x}$ catalytic cycle decreases by a factor of $\sim 50$ in the lower stratosphere as a result of the hydrolysis of $\mathrm{N}_{2} \mathrm{O}_{5}$ that converts $\mathrm{NO}_{x}$ to nitric acid. The catalytic cycle rate limited by $\mathrm{HO}_{x}$ remains largely unaffected. Catalytic control of ozone thereby transitions from $\mathrm{HO}_{x}$ control to halogen radical control with an overall increase in the ozone loss rate of nearly

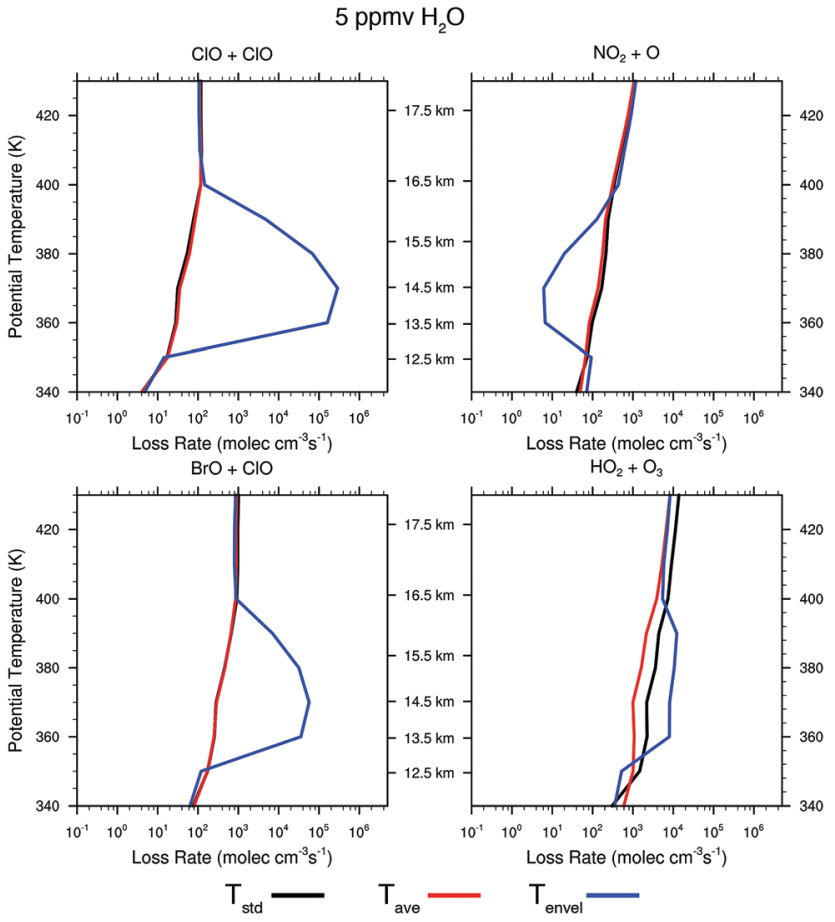

Fig. 11 The rate of ozone loss for the four major catalytic cycles rate limited by $\mathrm{ClO}+\mathrm{ClO}, \mathrm{ClO}+\mathrm{BrO}, \mathrm{NO}_{2}+\mathrm{O}$, and $\mathrm{HO}_{2}+\mathrm{O}_{3}$ are displayed for three different temperature profiles. The black line corresponds to the ozone loss rate for the temperature distribution $T_{\text {std }}$ as displayed in Fig. 10; the red line corresponds to the temperature $T_{\text {avg; }}$ and the blue line to the temperature distribution $T_{\text {env }}$.

two orders of magnitude in the 12 to $16 \mathrm{~km}$ range. This response of the rate limiting catalytic loss rates of ozone is a remarkable characteristic of the system. Specifically, by virtually no response to decreasing temperatures until a threshold temperature is reached (corresponding remarkably to $\sim T_{\text {avg }}$ ) and then for very small decreases in temperature there is a profound change in the ozone loss rate and, indeed, in the catalytic cycles that dominate ozone loss. This response is critically important for establishing the quantitative level of risk for stratospheric ozone loss over the central United States in summer.

2.6.2 Response of catalytic ozone loss to increased water vapor concentrations resulting from convective injection. Fig. 12 addresses the influence of convectively injected water vapor on the same four catalytic cycles for the three temperature profiles $T_{\mathrm{std}}$, $T_{\text {avg }}$, and $T_{\text {env. }}$ Fig. 12, panel A, displays the model runs with convectively injected water vapor raised to and maintained at $10 \mathrm{ppmv}$ throughout a $6 \mathrm{~km}$ layer in the lower stratosphere between 12 and $18 \mathrm{~km}$. Here we model $6 \mathrm{~km}$ of elevated water vapor to demonstrate the response as a function of altitude. Stratospheric water vapor values over the US in summer significantly higher than 10 ppmv have been observed by the MLS satellite instrument as well as in situ aircraft instruments. ${ }^{66}$ Thus in Fig. 12, panel B, we present the four major rate limiting steps for the case of 20 ppmv of convectively injected water vapor with the same three temperature distributions $T_{\text {std }}, T_{\text {avg }}$, and $T_{\text {env }}$.

For the case of $T_{\text {std }}$, there is virtually no response to water vapor raised to $10 \mathrm{ppmv}$ and only marginal response for $20 \mathrm{ppmv}$. 
A

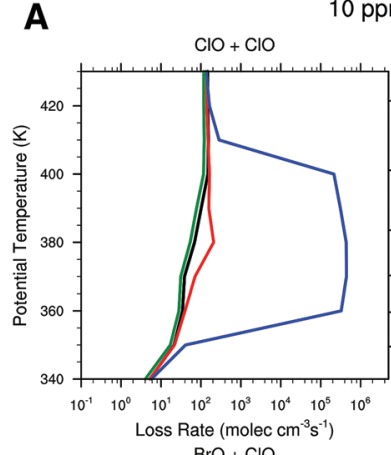

10 ppmv $\mathrm{H}_{2} \mathrm{O}$

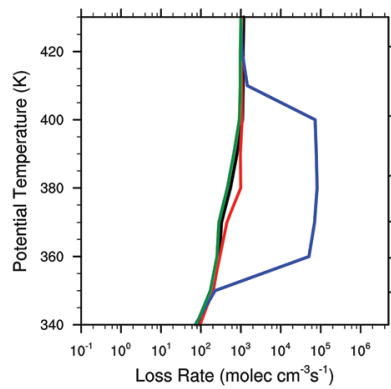

B

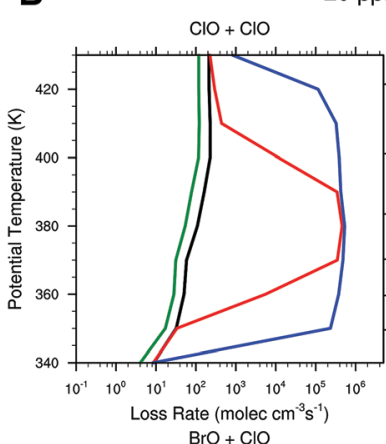

20 ppmv $\mathrm{H}_{2} \mathrm{O}$
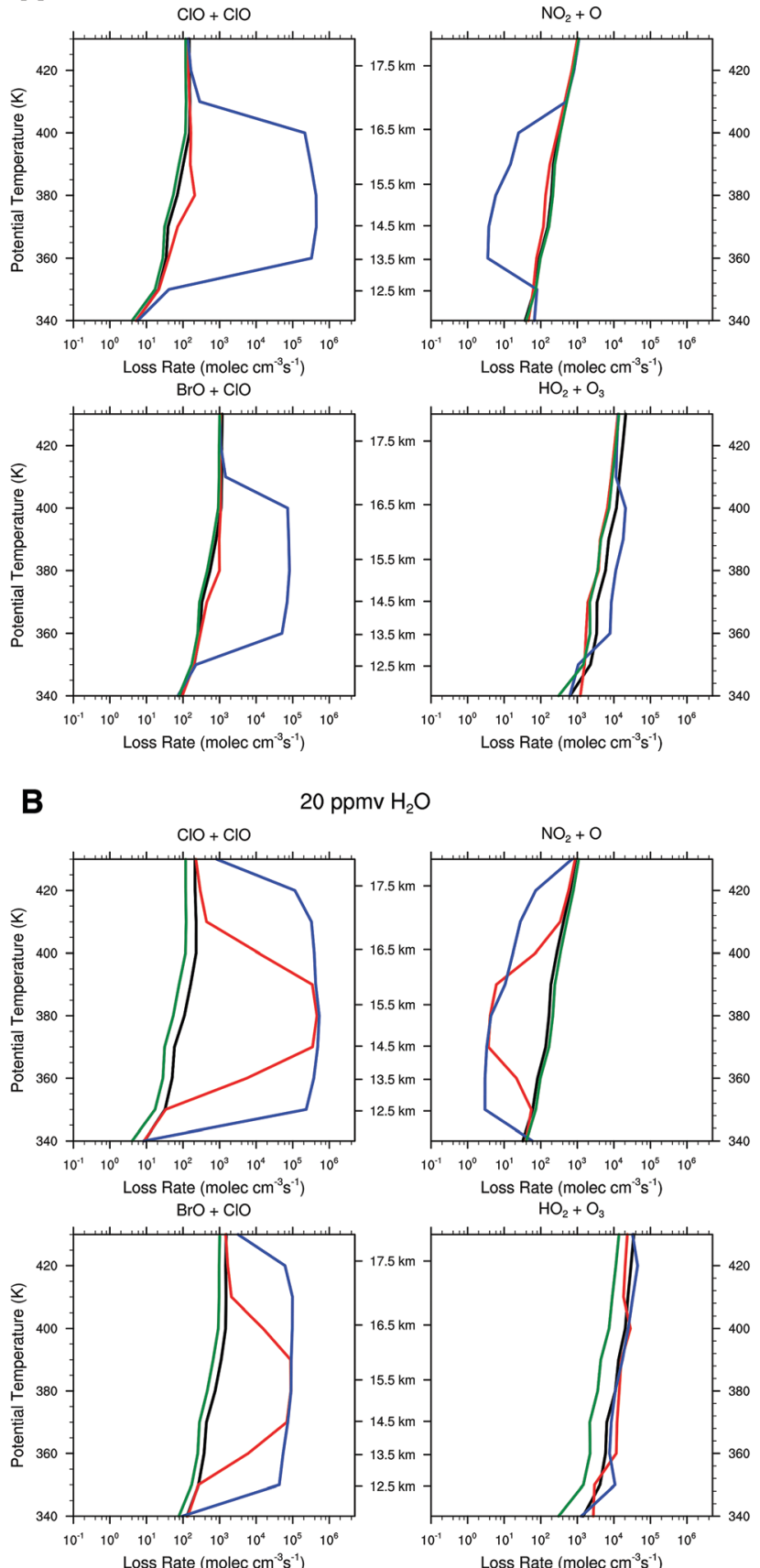

Fig. 12 Panel A displays the ozone loss rate for the four catalytic cycles rate limited by $\mathrm{ClO}+\mathrm{ClO}, \mathrm{ClO}+\mathrm{BrO}, \mathrm{NO}_{2}+\mathrm{O}$, and $\mathrm{HO}_{2}+\mathrm{O}_{3}$ for the case of 10 ppmv of $\mathrm{H}_{2} \mathrm{O}$ convectively injected into the stratosphere for the three temperature distributions $T_{\text {std }}, T_{\text {avg }}$ and $T_{\text {envi }}$ all with the $\mathrm{HCl}$ distribution $[\mathrm{HCl}]_{\text {mid. }}$. Panel $\mathrm{B}$ displays the ozone loss rate for the same four catalytic cycles but for 20 ppmv $\mathrm{H}_{2} \mathrm{O}$ with the three temperature distributions $T_{\text {std, }}, T_{\text {avg }}$ and $T_{\text {envi }}$ all with the $\mathrm{HCl}$ distribution $[\mathrm{HCl}]_{\text {mid. }}$. In each case the reference line in green corresponds to the unperturbed case with $5 \mathrm{ppmv}$ $\mathrm{H}_{2} \mathrm{O}$ and $T_{\text {std. }}$. In each case the black line corresponds to $T_{\text {std; }}$, the red line to $T_{\text {avg, }}$ and the blue line to $T_{\text {env. }}$.

For the temperature distribution represented by the observed temperature $T_{\text {avg }}$ over the US in summer, the presence of convected water vapor at a mixing ratio of $10 \mathrm{ppmv}$ increases the rate of ozone loss by the $\mathrm{ClO}+\mathrm{ClO}$ rate limiting step only marginally, but at $20 \mathrm{ppmv} \mathrm{H}_{2} \mathrm{O}$ the $\mathrm{ClO}+\mathrm{ClO}$ rate increases by nearly four orders of magnitude between 14 and $16 \mathrm{~km}$, while increasing the $\mathrm{ClO}+\mathrm{BrO}$ RLS by more than two orders of magnitude. In sharp contrast, for the observed temperature profile $T_{\text {env }}$, at $10 \mathrm{ppmv}$ the $\mathrm{ClO}+\mathrm{ClO}$ RLS increases by four orders of magnitude and the ClO + BrO RLS step increases by two orders of magnitude over the significantly wider altitude range from 12 to $18 \mathrm{~km}$. It is clear from comparison of panels A and B in Fig. 11 that convective injection of water vapor most significantly changes the ozone loss rate for $T_{\text {avg }}$, but that at $T_{\text {env }}$, either 10 ppmv or $20 \mathrm{ppmv}$ of convected water serves to convert a dominant fraction of inorganic chlorine to free radical form, ClO. For both $10 \mathrm{ppmv}$ and 20 ppmv $\mathrm{H}_{2} \mathrm{O}$, the $\mathrm{HO}_{2}+\mathrm{O}_{3} \mathrm{RLS}$ is essentially unaffected. The NOx catalytic cycle rate limited by $\mathrm{NO}_{2}+\mathrm{O}$ decreases by a factor of fifty for $T_{\text {env }}$ at $10 \mathrm{ppmv}_{2} \mathrm{O}$, but is unaffected at $T_{\text {avg. }}$. At $20 \mathrm{ppmv}$, $\mathrm{NO}_{2}+\mathrm{O}$ decreases by a factor of fifty for $T_{\mathrm{avg}}$ but over a more limited altitude than is the case for $T_{\text {env }}$.

2.6.3 Response of catalytic ozone loss to the range of observed $\mathrm{HCl}$ at temperatures $\boldsymbol{T}_{\mathrm{avg}}$, and $\boldsymbol{T}_{\mathrm{env}}$ for increased water vapor concentrations resulting from convective injection. Fig. 13, panel A, displays the major rate limiting catalytic cycles for the three $\mathrm{HCl}$ mixing ratio profiles $[\mathrm{HCl}]_{\text {lower env }},[\mathrm{HCl}]_{\text {mid }}$, and $[\mathrm{HCl}]_{\text {upper env }}$, displayed in Fig. 9 for the temperature distribution $T_{\text {avg }}$ and for 10 ppmv of convectively injected water vapor. An inspection of panel A reveals that at $10 \mathrm{ppmv} \mathrm{H}_{2} \mathrm{O}$ and $T_{\text {avg }}$, the $\mathrm{ClO}+\mathrm{ClO} \mathrm{RLS}$ is only marginally enhanced as is the $\mathrm{ClO}+\mathrm{BrO} \mathrm{RLS}$. But it is important to note that the $\mathrm{HO}_{x} \mathrm{RLS} \mathrm{HO}_{2}+\mathrm{O}_{3}$ still dominates the catalytic loss of ozone in the lower stratosphere. The $\mathrm{NO}_{x} \mathrm{RLS}$ is both largely unaffected and plays no significant quantitative role in the net $\mathrm{O}_{3}$ loss rate.

Panel B in sharp contrast, displays a dramatic increase in the $\mathrm{ClO}+\mathrm{ClO}$ RLS of some five orders of magnitude triggered by the small decrease in temperature profile between the observed temperatures of $T_{\text {avg }}$ and $T_{\text {env }}$. Inspection of panel C corresponding to 20 ppmv of convectively injected water vapor at $T_{\text {avg }}$ underscores the remarkable behavior of the heterogeneous catalytic mechanism of inorganic chlorine conversion to free radical form displayed schematically in Fig. 8. Specifically, that the threshold for rapid conversion of inorganic chlorine to free radical form can be accomplished either by small decreases in temperature or by increases in the water vapor concentration. Panel D of Fig. 13, corresponding to $20 \mathrm{ppmv}$ of convectively injected water vapor for the observed temperature distribution $T_{\text {env }}$ of Fig. 10, expands markedly the altitude range of accentuated ozone catalytic loss by both the $\mathrm{ClO}+\mathrm{ClO}$ and $\mathrm{ClO}+\mathrm{BrO}$ RLSs such that catalytic control of ozone passes from $\mathrm{HO}_{x}$ control to $\mathrm{CLO}_{x} / \mathrm{BrO}_{x}$ control and the net loss rate increases by more than two orders of magnitude.

2.6.4 Response of the stratospheric ozone vertical distribution to catalytic loss for the range of observed $\mathrm{HCl}$ at temperatures $T_{\text {avg }}$, and $T_{\text {env }}$ for the case of 20 ppmv $\mathrm{H}_{2} \mathrm{O}$ from convective injection. A critical quantitative factor in assessing the risk of significant stratospheric ozone loss over the central United States in summer is the available inorganic chlorine concentration in the lower stratosphere that is highly seasonally variable. The reason for this seasonal dependence of inorganic chlorine is that 
A

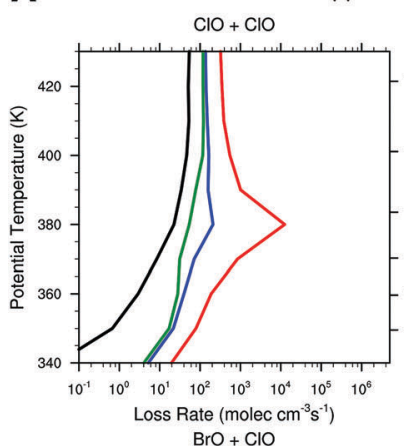

10 ppmv $\mathrm{H}_{2} \mathrm{O}$ Tavg

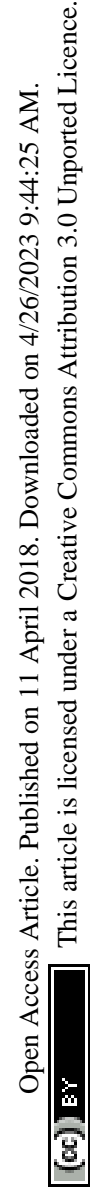

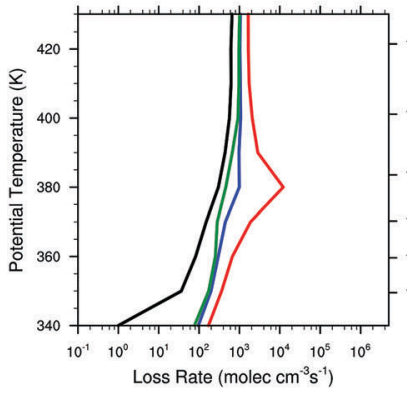

C

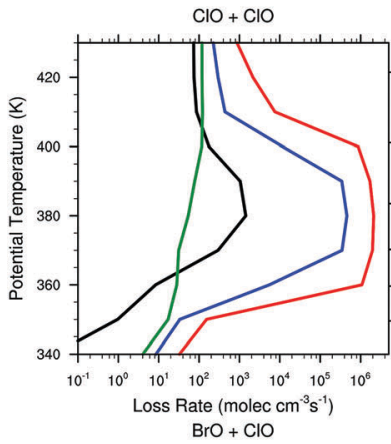

20 ppmv $\mathrm{H}_{2} \mathrm{O}$ Tavg
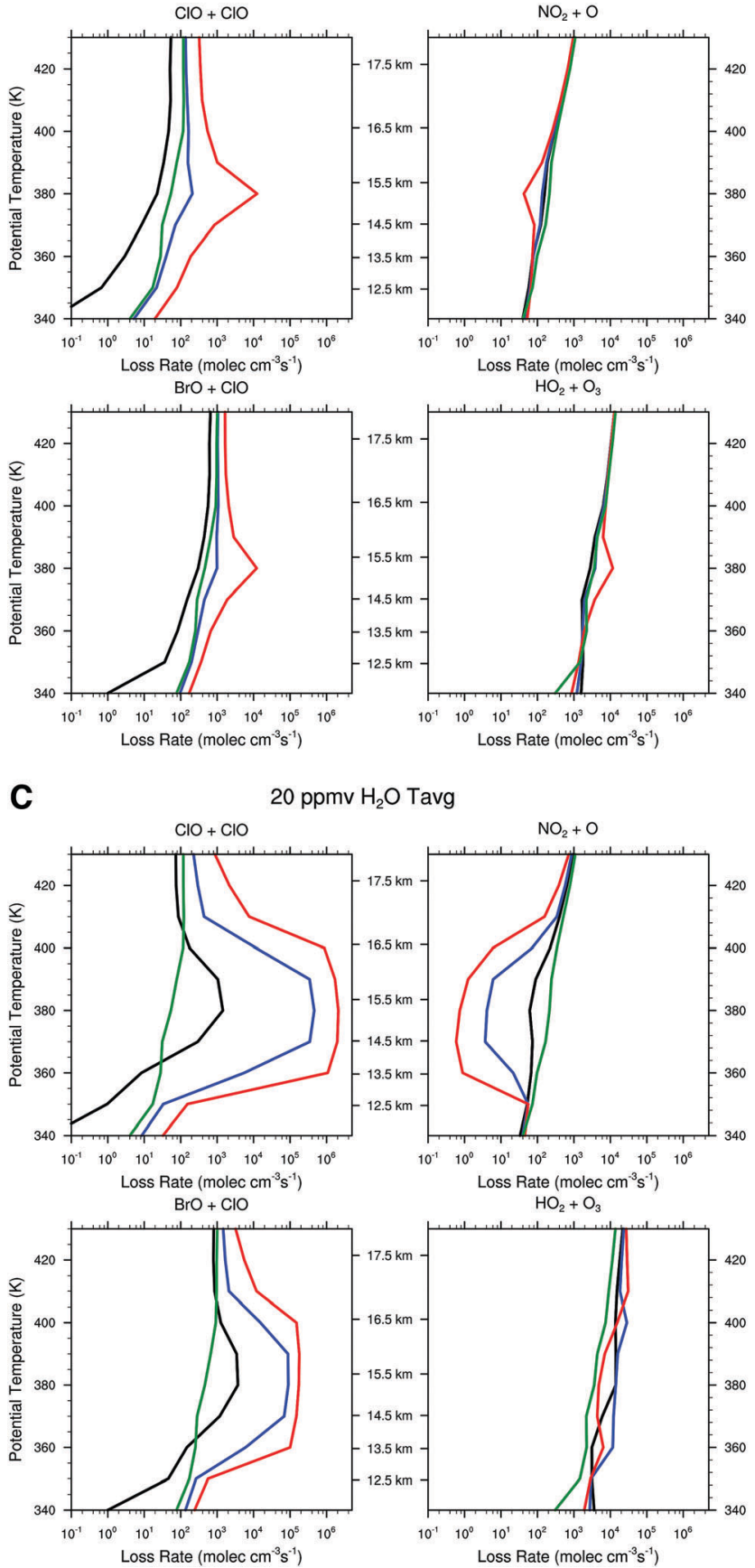

B

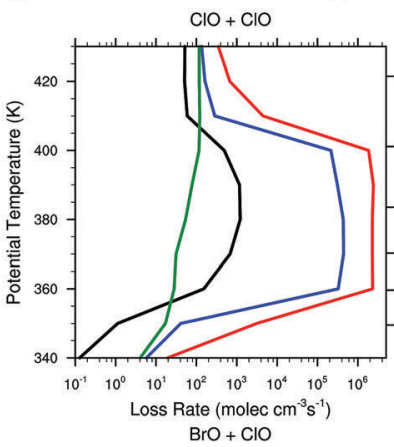

10 ppmv $\mathrm{H}_{2} \mathrm{O}$ Tenv


D

20 ppmv $\mathrm{H}_{2} \mathrm{O}$ Tenv


Fig. 13 The ozone loss as a function of altitude for combination of temperature and convectively injected water vapor are displayed in the four panels of the figure. Panel A displays the ozone loss rate for the for the four catalytic cycles rate limited by $\mathrm{ClO}+\mathrm{ClO}, \mathrm{ClO}+\mathrm{BrO}, \mathrm{NO}_{2}+\mathrm{O}_{1}$ and $\mathrm{HO} \mathrm{O}_{2}+\mathrm{O}_{3}$ for the case of 10 ppmv $\mathrm{H}_{2} \mathrm{O}$ with the temperature distribution $T_{\text {avg }}$ for the three $\mathrm{HCl}$ profiles $[\mathrm{HCl}]_{\text {lower env, }}[\mathrm{HCL}]_{\text {mid, }}$ and $[\mathrm{HCl}]_{\text {upper env }}$ shown respectively in green, black and red. Panel B for the same conditions as panel A with $T_{\text {env }}$ in place of $T_{\text {avg. }}$. Panel $C$ is identical to the case for panel A except 20 ppmv is used rather than $10 \mathrm{ppmv}$, and panel $\mathrm{D}$ introduces both $20 \mathrm{ppmv}$ and $T_{\text {env }}$ for the calculation defining the impact on the ozone distribution.

increased inorganic chlorine is brought to lower altitudes during the diabatic subsidence that is an intrinsic part of the Arctic winter vortex during the winter and early spring each year. This is followed by the meridional transport of higher $\mathrm{HCl}$ mixing ratios to midlatitudes of the Northern Hemisphere in the early summer that is the underlying cause of the large dynamic range in observed $\mathrm{HCl}$ mixing ratios displayed in Fig. 9.
We calculate next the impact on the ozone profile in response to the change in the rate limiting steps for the temperature profiles $T_{\text {avg }}$ and $T_{\text {env }}$ in the presence of convective injection of water vapor for the range in $\mathrm{HCl}$ from $[\mathrm{HCl}]_{\text {lower env }}$, to $[\mathrm{HCl}]_{\text {upper env }}$. Fig. 14 presents the model calculated ozone profiles for each of the temperature profiles two weeks after the convective injection of water vapor (the nominal period of time that a convectively 
A

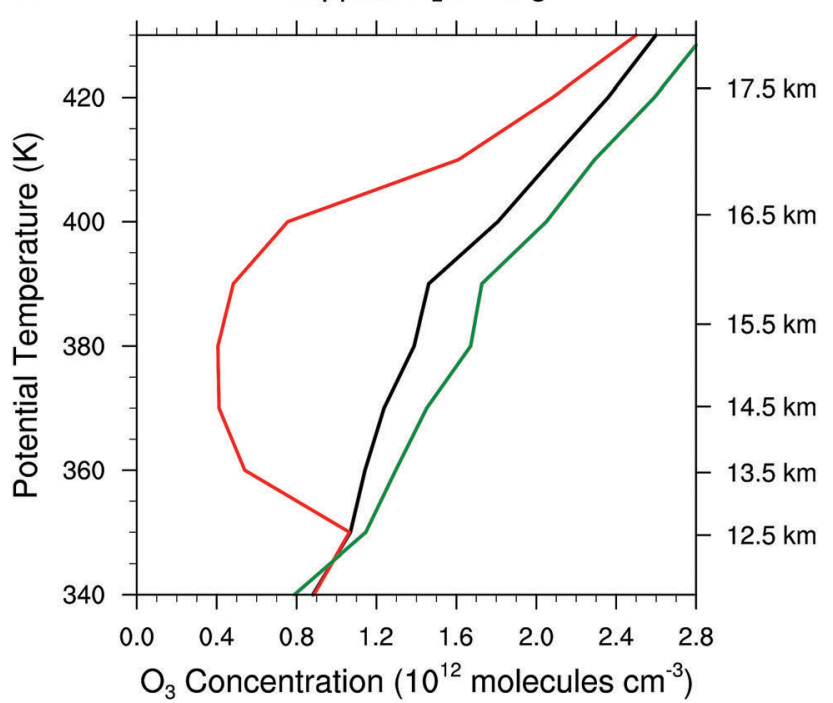

B



C

\begin{tabular}{|c|c|c|c|c|c|c|c|}
\hline \multicolumn{2}{|c|}{ Fractional Ozone Loss Between 12 and $18 \mathrm{~km}$} & \multirow{2}{*}{$\frac{20 \text { ppmv } \mathrm{H}_{2} \mathrm{O}}{\mathrm{T}_{\text {avg }}-34.64}$} & \multicolumn{5}{|c|}{ Fractional Loss in Total Ozone Column Concentration 20 ppmv $\mathrm{H}_{2} \mathrm{O}$} \\
\hline$[\mathrm{HCl}]_{\text {lower env }} \mathrm{T}_{\text {avg }}-2.48$ & {$[\mathrm{HCl}]_{\text {upper env }}$} & & {$[\mathrm{HCl}]_{\text {lower env }} \mathrm{T}_{\mathrm{a}}$} & g -0.24 & {$[\mathrm{HCl}]_{\text {upper env }}$} & avg & -3.64 \\
\hline$[\mathrm{HCl}]_{\text {lower env }} \mathrm{T}_{\text {env }}-2.52$ & {$[\mathrm{HCl}]_{\text {upper env }}$} & $\mathrm{T}_{\text {env }}-66.95$ & {$[\mathrm{HCl}]_{\text {lower env }} \mathrm{T}$} & -0.27 & {$[\mathrm{HCl}]_{\text {upper env }}$} & env & -7.82 \\
\hline
\end{tabular}

Fig. 14 Panel A displays the impact of the sum of the rate limiting steps for the case of $20 \mathrm{ppmv} \mathrm{H}_{2} \mathrm{O}$ and $T_{\text {avg }}$ for $[\mathrm{HCl}]_{\text {lower env }}$ displayed in black relative to the unperturbed reference case in green and for $[\mathrm{HCl}]_{\text {upper env }}$ displayed in red. Panel $\mathrm{B}$ displays the same conditions as panel $\mathrm{A}$ except for the temperature distribution $T_{\text {env }}$ rather than $T_{\text {avg. }}$. Panel $C$ tabulates the fractional ozone loss between 12 and 18 kilometers and the fraction decrease in the total ozone column density for the temperatures $T_{\text {avg }}$ and $T_{\text {env }}$ relative to the unperturbed reference case in green.

influenced domain resides within the anti-cyclonic circulation) with water vapor elevated to $20 \mathrm{ppmv}$ from 12 to $18 \mathrm{~km}$. We do this for a single convective event, recognizing that on average 2000 convective events extend above approximately $16 \mathrm{~km}$ in a given summer. For the case of $T_{\text {avg }}$ in Fig. 14 panel A, the convective injection yields a fractional reduction in ozone between 12 and $18 \mathrm{~km}$ of $-2.5 \%$ for the $[\mathrm{HCl}]_{\text {lower env }}$ case, but for the $[\mathrm{HCl}]_{\text {upper env }}$ case, the fractional reduction in ozone between 12 and $18 \mathrm{~km}$ is $-34.6 \%$. This corresponds to a decrease in the total ozone column concentration of $-3.6 \%$. As treated in Section 3, this has significant consequences for human health. Convective injection of water with the observed envelope temperature, $T_{\text {env }}$, results in the catalytic loss rate increasing markedly over a significantly larger altitude domain such that the fractional loss of ozone over the altitude range 12 to $18 \mathrm{~km}$ is $67 \%$ and the fraction loss of total ozone column is $7.8 \%$ with a corresponding decrease in ozone as a function of altitude. Panel C of Fig. 14 presents a table of the fractional loss of ozone between 12 and $18 \mathrm{~km}$ for the cases spanning the range of observed $\mathrm{HCl}$ mixing ratios from $[\mathrm{HCl}]_{\text {lower env }}$, to $[\mathrm{HCl}]_{\text {upper env }}$, for both the observed $T_{\text {avg }}$ and $T_{\text {env }}$ for convectively injected $\mathrm{H}_{2} \mathrm{O}$ at $20 \mathrm{ppmv}$. The table also summarizes the corresponding reduction in total ozone column concentration.

\section{Human health implications}

A major factor underpinning the fact that the ozone shield is the most delicate aspect of habitability on the planet's surface is the fact that if the stratospheric ozone column were brought to standard temperature and pressure, that ozone column would be only $\sim 0.5 \mathrm{~cm}$ in depth. Moreover, detailed medical research has demonstrated that a $1 \%$ reduction in column ozone concentration over the US translates to a $3 \%$ increase in

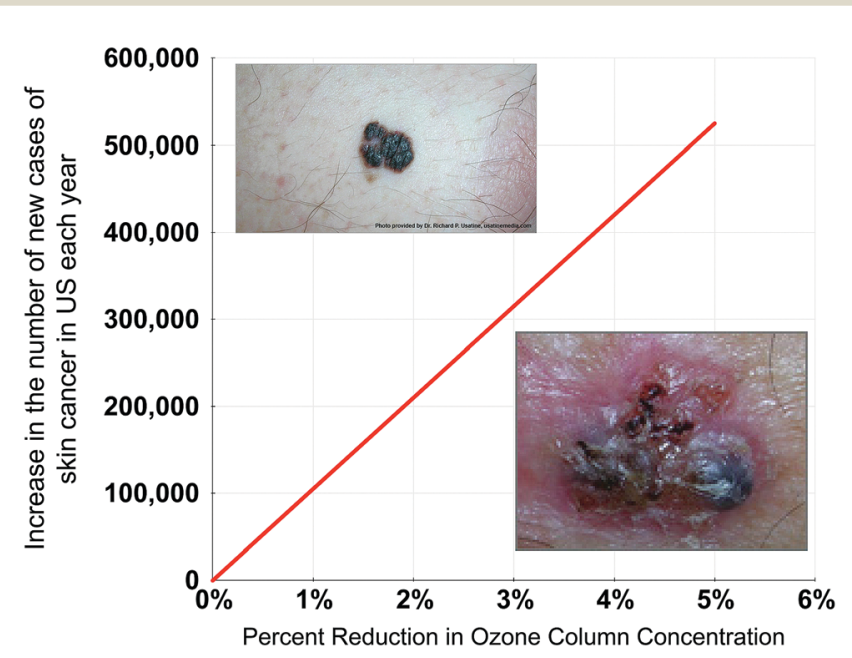

Fig. 15 Skin cancer is primarily of two forms: melanoma displayed in the upper left, and carcinoma displayed in the lower right. Skin cancer incidence has increased 300\% in the US since 1992 and now constitutes 3.5 million new cases a year. A fractional decrease in column ozone of $1 \%$ translates to a fractional increase of $3 \%$ in skin cancer incidence. This provides the information to plot the increase in the number of skin cancer cases annually vs. the percentage reduction in ozone column concentration displayed here. 
new skin cancer cases each year. Given that the incidence of skin cancer in the US has increased by 300\% since 1992 to 3.5 million new cases a year, we can calculate the fractional increase in skin cancer incidence as a function of the percent decrease in column ozone-a result displayed in Fig. 15. This defines the accuracy with which the forecast of ozone column concentration changes must be quantitatively trusted in response to increased forcing of the climate by $\mathrm{CO}_{2}, \mathrm{CH}_{4}, \mathrm{~N}_{2} \mathrm{O}$, etc.

\section{Conclusions}

The discovery of deep stratospheric convective injection of water vapor over the central United States in summer was not predicted nor was the risk for ozone loss associated with convective injection incorporated into stratospheric research planning. Given the development of sophisticated data analyses employing the NEXRAD weather radar network and the availability of high spatial resolution, high accuracy in situ temperature data, what has now emerged is a new understanding of the remarkable coincidence between the conditions present in the lower stratosphere over the US in summer, and the trigger point for dramatically enhanced catalytic loss rates of ozone resulting from the temperature-water vapor kinetics of heterogeneous catalytic conversion of inorganic chlorine to free radical form on simple sulfate-water aerosols followed by the homogeneous catalytic removal of ozone by the two halogen catalytic cycles engaging the ClOOCl dimer, ${ }^{46}$ and the coupled $\mathrm{ClO} / \mathrm{BrO}$ catalytic cycle. ${ }^{47}$

The abrupt threshold for markedly enhanced catalytic loss of ozone as a function of temperature alone is quantitatively displayed in Fig. 11. The response of catalytic ozone loss to combinations of temperature and water vapor is displayed in Fig. 12. Finally, Fig. 13 captures the response of ozone loss rates to combinations of temperature, water vapor and available $\mathrm{HCl}$ - the dominant form of inorganic chlorine in the stratosphere. Of particular concern is:

(1) Warming of the surface waters of the Gulf of Mexico as a result of the increased trapping of infrared radiation by greenhouse gases fuels both the increased frequency and intensity of the convective storm systems over the Great Plains of the United States;

(2) Increased forcing of the climate by carbon dioxide and methane leads to cooling of the stratosphere-as would the loss of ozone in the critical altitude region between 14 and $18 \mathrm{~km}-$ thereby potentially shifting the stratosphere towards a temperature domain capable of more frequently initiated heterogeneous catalytic conversion of $\mathrm{Cl}_{\mathrm{y}}$ to $\mathrm{ClO}$ and, in turn, increasing the rate of ozone loss;

(3) Uncertainty in forecasting the rate of increase in the intensity and frequency of severe storm systems over the central US in summer resulting from increased forcing of the climate in combination with uncertainties in the multi-decadal changes in chlorine loading of the stratosphere resulting from the global ban on CFCs and halons invoked by the Montreal Protocol;

(4) Acknowledgement of the response of the rate of ozone loss in the lower stratosphere to enhanced sulfate loading from volcanic eruptions or overt sulfate addition for climate engineering that act in concert with temperature and water vapor in controlling the rate of catalytic ozone loss;

(5) Recognition that volcanic eruptions can contain significantly elevated quantities of hydrogen halides in addition to sulfur dioxide. For example, elevated $\mathrm{Cl}_{\mathrm{y}}$ was detected in the stratospheric volcanic clouds of El Chichón (1982) and Hekla (2000). ${ }^{76-79}$ From petrology, a number of historic eruptions are known to have produced large quantities of $\mathrm{HCl}$ and $\mathrm{HBr}$, which would have exceeded peak anthropogenic Equivalent Effective Stratospheric Chlorine (EESC) that accounts for both chlorine and bromine levels, if even a small fraction of their emissions partitioned to the stratosphere. ${ }^{80-83}$ A 2016 analysis of MLS satellite observations confirms that the stratospheric injection of halogens is more frequent than previously believed; ${ }^{84}$ and

(6) Consideration of the marked sensitivity of human skin cancer incidence, in addition to increased risks to livestock and decreased staple crop production, to small increases in UV dosage levels.

\section{Conflicts of interest}

There are no conflicts to declare.

\section{Acknowledgements}

This work has been supported by the National Aeronautics and Space Administration (NASA) under NASA award numbers NNX15AF60G (UV Absorption Cross Sections and Equilibrium Constant of ClOOCl Determined from New Laboratory Spectroscopy Studies of ClOOCl and ClO) and NNX15AD87G (New Laboratory Bromine Kinetics for Improving Models and Projections of Stratospheric Ozone), and a grant from the National Science Foundation (NSF) Arctic Observing Network (AON) Program under NSF award number 1203583 (Collaborative Research: Multi-Regional Scale Aircraft Observations of Methane and Carbon Dioxide Isotopic Fluxes in the Arctic).

\section{References}

1 J. Hansen, M. Sato, P. Hearty, R. Ruedy, M. Kelley, V. Masson-Delmotte, G. Russell, G. Tselioudis, J. Cao, E. Rignot, I. Velicogna, B. Tormey, B. Donovan, E. Kandiano, K. von Schuckmann, P. Kharecha, A. N. Legrande, M. Bauer and K.-W. Lo, Ice melt, sea level rise and superstorms: evidence from paleoclimate data, climate modeling, and modern observations that $2{ }^{\circ} \mathrm{C}$ global warming could be dangerous, Atmos. Chem. Phys., 2016, 16(6), 3761-3812.

2 J. Hansen, M. Sato, G. Russell and P. Kharecha, Climate sensitivity, sea level and atmospheric carbon dioxide, Philos. Trans. R. Soc., A, 2013, 371, 20120294.

3 D. B. Kirk-Davidoff, E. J. Hintsa, J. G. Anderson and D. W. Keith, The effect of climate change on ozone depletion through changes in stratospheric water vapour, Nature, 1999, 402, 399-401. 
4 J. G. Anderson, D. K. Weisenstein, K. P. Bowman, C. R. Homeyer, J. B. Smith, D. M. Wilmouth, D. S. Sayres, J. E. Klobas, S. S. Leroy, J. A. Dykema and S. C. Wofsy, Stratospheric ozone over the United States in summer linked to observations of convection and temperature via chlorine and bromine catalysis, Proc. Natl. Acad. Sci. U. S. A., 2017, 114, E4905-E4913.

5 K. M. Walter, L. C. Smith and F. S. Chapin, Methane bubbling from northern lakes: present and future contributions to the global methane budget, Philos. Trans. R. Soc., A, 2007, 365, 1657-1676.

6 R. Commane, J. Lindaas, J. Benmergui, K. A. Luus, R. Y. Chang, B. C. Daube, E. S. Euskirchen, J. M. Henderson, A. Karion, J. B. Miller, S. M. Miller, N. C. Parazoo, J. T. Randerson, C. Sweeney, P. Tans, K. Thoning, S. Veraverbeke, C. E. Miller and S. C. Wofsy, Carbon dioxide sources from Alaska driven by increasing early winter respiration from Arctic tundra, Proc. Natl. Acad. Sci. U. S. A., 2017, 114, 5361-5366.

7 B. Buffett and D. Archer, Global inventory of methane clathrate: sensitivity to changes in the deep ocean, Earth Planet. Sci. Lett., 2004, 227, 185-199.

8 IPCC, 2007: Climate Change 2007: The Physical Science Basis, in Contribution of Working Group I to the Fourth Assessment Report of the Intergovernmental Panel on Climate Change, ed. S. Solomon, D. Qin, M. Manning, Z. Chen, M. Marquis, K. B. Averyt, M. Tignor, and H. L. Miller, Cambridge University Press, New York, 2007.

9 IPCC, 2013: Climate Change 2013: The Physical Science Basis: Working Group I Contribution to the Fifth Assessment Report of the Intergovernmental Panel on Climate Change, ed. T. F. Stocker, D. Qin, G.-K. Plattner, M. Tignor, S. K. Allen, J. Boschung, A. Nauels, Y. Xia, V. Bex, and P. M. Midgley, Cambridge University Press, New York, 2013.

10 E. A. Schuur, A. D. McGuire, C. Schädel, G. Grosse, J. W. Harden, D. J. Hayes, G. Hugelius, C. D. Koven, P. Kuhry, D. M. Lawrence, S. M. Natali, D. Olefeldt, V. E. Romanovsky, K. Schaefer, M. R. Turetsky, C. C. Treat and J. E. Vonk, Climate change and the permafrost carbon feedback, Nature, 2015, 520, 171-179.

11 S. A. Zimov, E. A. Schuur and F. S. Chapin, Permafrost and the global carbon budget, Science, 2006, 312, 1612-1613.

12 S. Palmer, A. Shepherd, P. Nienow and I. Joughin, Seasonal speedup of the Greenland Ice Sheet linked to routing of surface water, Earth Planet. Sci. Lett., 2011, 302, 423-428.

13 I. Velicogna, Increasing rates of ice mass loss from the Greenland and Antarctic ice sheets revealed by GRACE, Geophys. Res. Lett., 2009, 36, L19503.

14 A. Dutton, A. E. Carlson, A. J. Long, G. A. Milne, P. U. Clark, R. DeConto, B. P. Horton, S. Rahmstorf and M. E. Raymo, Sea-level rise due to polar ice-sheet mass loss during past warm periods, Science, 2015, 349, aaa4019.

15 M. E. Raymo and J. X. Mitrovica, Collapse of polar ice sheets during the stage 11 interglacial, Nature, 2012, 483, 453-456.

16 T. F. Hanisco, E. J. Moyer, E. M. Weinstock, J. M. St. Clair, D. S. Sayres, J. B. Smith, R. Lockwood, J. G. Anderson,
A. E. Dessler, F. N. Keutsch, J. R. Spackman, W. G. Read and T. P. Bui, Observations of deep convective influence on stratospheric water vapor and its isotopic composition, Geophys. Res. Lett., 2007, 34, L04814.

17 J. G. Anderson, D. M. Wilmouth, J. B. Smith and D. S. Sayres, UV dosage levels in summer: increased risk of ozone loss from convectively injected water vapor, Science, 2012, 337, 835-839.

18 C. R. Homeyer, L. L. Pan and M. C. Barth, Transport from convective overshooting of the extratropical tropopause and the role of large-scale lower stratosphere stability, J. Geophys. Res.: Atmos., 2014, 119, 2220-2240.

19 L. L. Pan, E. L. Atlas, R. J. Salawitch, S. B. Honomichl, J. F. Bresch, W. J. Randel, E. C. Apel, R. S. Hornbrook, A. J. Weinheimer, D. C. Anderson, S. J. Andrews, S. Baidar, S. P. Beaton, T. L. Campos, L. J. Carpenter, D. Chen, B. Dix, V. Donets, S. R. Hall, T. F. Hanisco, C. R. Homeyer, L. G. Huey, J. B. Jensen, L. Kaser, D. E. Kinnison, T. K. Koenig, J.-F. Lamarque, C. Liu, J. Luo, Z. J. Luo, D. D. Montzka, J. M. Nicely, R. B. Pierce, D. D. Riemer, T. Robinson, P. Romashkin, A. Saiz-Lopez, S. Schauffler, O. Shieh, M. H. Stell, K. Ullmann, G. Vaughan, R. Volkamer and G. Wolfe, The Convective Transport of Active Species in the Tropics (CONTRAST) Experiment, Bull. Am. Meteorol. Soc., 2017, 98, 106-128.

20 A. E. Gill, Some simple solutions for heat-induced tropical circulation, Q. J. R. Meteorol. Soc., 1980, 106, 447-462.

21 E. M. Weinstock, J. V. Pittman, D. S. Sayres, J. B. Smith, J. G. Anderson, S. C. Wofsy, I. Xueref, C. Gerbig, B. C. Daube, L. Pfister, E. C. Richard, B. A. Ridley, A. J. Weinheimer, H.-J. Jost, J. P. Lopez, M. Loewenstein and T. L. Thompson, Quantifying the impact of the North American monsoon and deep midlatitude convection on the subtropical lowermost stratosphere using in situ measurements, J. Geophys. Res., 2007, 112, D18310.

22 S. Solomon, Stratospheric ozone depletion: A review of concepts and history, Rev. Geophys., 1999, 37, 275-316.

23 D. W. Fahey, S. R. Kawa, E. L. Woodbridge, P. Tin, J. C. Wilson, H. H. Jonsson, J. E. Dye, D. Baumgardner, S. Borrmann, D. W. Toohey, L. M. Avallone, M. H. Proffitt, J. Margitan, M. Loewenstein, J. R. Podolske, R. J. Salawitch, S. C. Wofsy, M. K. W. Ko, D. E. Anderson, M. R. Schoeber and K. R. Chan, In situ measurements constraining the role of sulphate aerosols in mid-latitude ozone depletion, Nature, 1993, 363, 509-514.

24 R. J. Salawitch, D. K. Weisenstein, L. J. Kovalenko, C. E. Sioris, P. O. Wennberg, K. Chance, M. K. W. Ko and C. A. McLinden, Sensitivity of ozone to bromine in the lower stratosphere, Geophys. Res. Lett., 2005, 32, L05811.

25 S. Solomon, R. W. Portmann, R. R. Garcia, W. Randel, F. Wu, R. Nagatani, J. Gleason, L. Thomason, L. R. Poole and M. P. McCormick, Ozone depletion at mid-latitudes: coupling of volcanic aerosols and temperature variability to anthropogenic chlorine, Geophys. Res. Lett., 1998, 25, 1871-1874.

26 T. Canty, N. R. Mascioli, M. D. Smarte and R. J. Salawitch, An empirical model of global climate - part 1: a critical 
evaluation of volcanic cooling, Atmos. Chem. Phys., 2013, 13, 3997-4031.

27 S. Tilmes, R. R. Garcia, D. E. Kinnison, A. Gettelman and P. J. Rasch, Impact of geoengineered aerosols on the troposphere and stratosphere, J. Geophys. Res., 2009, 114, D12305.

28 C. G. McCormack, W. Born, P. J. Irvine, E. P. Achterberg, T. Amano, J. Ardron, P. N. Foster, J.-P. Gattuso, S. J. Hawkins, E. Hendy, W. D. Kissling, S. E. Lluch-Cota, E. J. Murphy, N. Ostle, N. J. P. Owens, R. I. Perry, H. O. Pörtner, R. J. Scholes, F. M. Schurr, O. Schweiger, J. Settele, R. K. Smith, S. Smith, J. Thompson, D. P. Tittensor, M. van Kleunen, C. Vivian, K. Vohland, R. Warren, A. R. Watkinson, S. Widdicombe, P. Williamson, E. Woods, J. J. Blackstock and W. J. Sutherland, Key impacts of climate engineering on biodiversity and ecosystems, with priorities for future research, J. Integr. Environ. Sci., 2016, 13, 103-128.

29 P. J. Crutzen, Albedo Enhancement by Stratospheric Sulfur Injections: A Contribution to Resolve a Policy Dilemma?, Clim. Change, 2006, 77, 211-220.

30 G. Pitari, V. Aquila, B. Kravitz, A. Robock, S. Watanabe, I. Cionni, N. D. Luca, G. D. Genova, E. Mancini and S. Tilmes, Stratospheric ozone response to sulfate geoengineering: results from the geoengineering Model Intercomparison Project (GeoMIP), J. Geophys. Res.: Atmos., 2014, 119, 2629-2653.

31 J. A. Dykema, D. W. Keith, J. G. Anderson and D. Weisenstein, Stratospheric controlled perturbation experiment: a small-scale experiment to improve understanding of the risks of solar geoengineering, Philos. Trans. R. Soc., A, 2014, 372, 20140059.

32 D. K. Weisenstein, D. W. Keith and J. A. Dykema, Solar geoengineering using solid aerosol in the stratosphere, Atmos. Chem. Phys., 2015, 15, 11835-11859.

33 Z. Feng, L. R. Leung, S. Hagos, R. A. Houze, C. D. Burleyson and K. Balaguru, More frequent intense and long-lived storms dominate the springtime trend in central US rainfall, Nat. Commun., 2016, 7, 13429.

34 M. K. Tippett, C. Lepore and J. E. Cohen, More tornadoes in the most extreme U.S. tornado outbreaks, Science, 2016, 354, 1419-1423.

35 N. S. Diffenbaugh, M. Scherer and R. J. Trapp, Robust increases in severe thunderstorm environments in response to greenhouse forcing, Proc. Natl. Acad. Sci. U. S. A., 2013, 110, 16361-16366.

36 R. J. Trapp and K. A. Hoogewind, The realization of extreme tornadic storm events under future anthropogenic climate change, J. Clim., 2016, 29, 5251-5265.

37 D. K. Weisenstein, G. K. Yue, M. K. W. Ko, N.-D. Sze, J. M. Rodriguez and C. J. Scott, A two-dimensional model of sulfur species and aerosols, J. Geophys. Res., 1997, 102, 13019-13035.

38 M. K. W. Ko, N.-D. Sze, C. J. Scott and D. K. Weisenstein, On the relation between stratospheric chlorine/bromine loading and short-lived tropospheric source gases, J. Geophys. Res., 1997, 102, 25507-25517.

39 C. P. Rinsland, D. K. Weisenstein, M. K. W. Ko, C. J. Scott, L. S. Chiou, E. Mahieu, R. Zander and P. Demoulin,
Post-Mount Pinatubo eruption ground-based infrared stratospheric column measurements of $\mathrm{HNO}_{3}, \mathrm{NO}$, and $\mathrm{NO}_{2}$ and their comparison with model calculations, J. Geophys. Res., 2003, 108, 4437.

40 M. A. Weinstock, Overview of ultraviolet radiation and cancer: what is the link? How are we doing?, Environ. Health Perspect., 1995, 103, 251-254.

41 T. L. Diepgen and V. Mahler, The epidemiology of skin cancer, Br. J. Dermatol., 2002, 146, 1-6.

42 Y. Matsumura and H. N. Ananthaswamy, Toxic effects of ultraviolet radiation on the skin, Toxicol. Appl. Pharmacol., 2004, 195, 298-308.

43 M. Tevini and A. H. Teramura, UV-B effects on terrestrial plants, Photochem. Photobiol., 1989, 50, 479-487.

44 M. J. Molina and F. S. Rowland, Stratospheric sink for chlorofluoromethanes: chlorine atom-catalysed destruction of ozone, Nature, 1974, 249, 810-812.

45 S. Solomon, R. R. Garcia, F. S. Rowland and D. J. Wuebbles, On the depletion of Antarctic ozone, Nature, 1986, 321, 755-758.

46 L. T. Molina and M. J. Molina, Production of chlorine oxide $\left(\mathrm{Cl}_{2} \mathrm{O}_{2}\right)$ from the self-reaction of the chlorine oxide (ClO) radical, J. Phys. Chem., 1987, 91, 433-436.

47 M. B. McElroy, R. J. Salawitch, S. C. Wofsy and J. A. Logan, Reductions of Antarctic ozone due to synergistic interactions of chlorine and bromine, Nature, 1986, 321, 759-762.

48 J. G. Anderson, W. H. Brune and D. W. Toohey, Free radicals within the Antarctic vortex: the role of CFCs in Antarctic ozone loss, Science, 1991, 251, 39-46.

49 W. H. Brune, D. W. Toohey, J. G. Anderson and K. R. Chan, In situ observations of $\mathrm{ClO}$ in the Arctic stratosphere: ER-2 aircraft results from $59^{\circ} \mathrm{N}$ to $80^{\circ} \mathrm{N}$ latitude, Geophys. Res. Lett., 1990, 17, 505-508.

50 R. M. Stimpfle, R. C. Cohen, G. P. Bonne, P. B. Voss, K. K. Perkins, L. C. Koch, J. G. Anderson, R. J. Salawitch, S. A. Lloyd, R. S. Gao, L. A. Del Negro, E. R. Keim and T. P. Bui, The coupling of $\mathrm{ClONO}_{2}, \mathrm{ClO}$, and $\mathrm{NO}_{2}$ in the lower stratosphere from in situ observations using the NASA ER-2 aircraft, J. Geophys. Res., 1999, 104, 26705-26714.

51 P. A. Newman, N. R. Harris, A. Adriani, G. T. Amanatidis, J. G. Anderson, G. O. Braathen, W. H. Brune, K. S. Carslaw, M. S. Craig, P. L. DeCola, M. Guirlet, R. S. Hipskind, M. J. Kurylo, H. Küllmann, N. Larsen, G. J. Mégie, J.-P. Pommereau, L. R. Poole, M. R. Schoeberl, F. Stroh, O. B. Toon, C. R. Trepte and M. Van Roozendael, An overview of the SOLVE/THESEO 2000 campaign, J. Geophys. Res., 2002, $107,8259$.

52 T. F. Hanisco, J. B. Smith, R. M. Stimpfle, D. M. Wilmouth, K. K. Perkins, J. R. Spackman, J. G. Anderson, D. Baumgardner, B. Gandrud, C. R. Webster, S. Dhaniyala, K. A. McKinney and T. P. Bui, Quantifying the rate of heterogeneous processing in the Arctic polar vortex with in situ observations of $\mathrm{OH}$, J. Geophys. Res., 2002, 107, 8278.

53 R. M. Stimpfle, D. M. Wilmouth, R. J. Salawitch and J. G. Anderson, First measurements of ClOOCl in the 
stratosphere: the coupling of $\mathrm{ClOOCl}$ and $\mathrm{ClO}$ in the Arctic polar vortex, J. Geophys. Res., 2004, 109, D03301.

54 D. M. Wilmouth, R. M. Stimpfle, J. G. Anderson, J. W. Elkins, D. F. Hurst, R. J. Salawitch and L. R. Lait, Evolution of inorganic chlorine partitioning in the Arctic polar vortex, J. Geophys. Res., 2006, 111, D16308.

55 G. L. Manney, M. L. Santee, M. Rex, N. J. Livesey, M. C. Pitts, P. Veefkind, E. R. Nash, I. Wohltmann, R. Lehmann, L. Froidevaux, L. R. Poole, M. R. Schoeberl, D. P. Haffner, J. Davies, V. Dorokhov, H. Gernandt, B. Johnson, R. Kivi, E. Kyrö, N. Larsen, P. F. Levelt, A. Makshtas, C. T. McElroy, H. Nakajima, M. C. Parrondo, D. W. Tarasick, P. von der Gathen, K. A. Walker and N. S. Zinoviev, Unprecedented Arctic ozone loss in 2011, Nature, 2011, 478, 469-475.

56 S. Solomon, R. W. Portmann, R. R. Garcia, L. W. Thomason, L. R. Poole and M. P. McCormick, The role of aerosol variations in anthropogenic ozone depletion at northern midlatitudes, J. Geophys. Res., 1996, 101, 6713-6727.

57 Q. Shi, J. T. Jayne, C. E. Kolb, D. R. Worsnop and P. Davidovits, Kinetic model for reaction of $\mathrm{ClONO}_{2}$ with $\mathrm{H}_{2} \mathrm{O}$ and $\mathrm{HCl}$ and $\mathrm{HOCl}$ with $\mathrm{HCl}$ in sulfuric acid solutions, J. Geophys. Res., 2001, 106, 24259-24274.

58 K. Drdla, Temperature thresholds for polar stratospheric ozone, Trans., Am. Geophys. Union, 2005, 86, Abstract A31D-03.

59 K. Drdla and R. Müller, Temperature thresholds for chlorine activation and ozone loss in the polar stratosphere, Ann. Geophys., 2012, 30, 1055-1073.

60 J. B. Burkholder, S. P. Sander, J. Abbatt, J. R. Barker, R. E. Huie, C. E. Kolb, M. J. Kurylo, V. L. Orkin, D. M. Wilmouth and P. H. Wine, Chemical Kinetics and Photochemical Data for Use in Atmospheric Studies, Evaluation No. 18, JPL Publication 15-10, Jet Propulsion Laboratory, Pasadena, 2015.

61 P. O. Wennberg, R. C. Cohen, R. M. Stimpfle, J. P. Koplow, J. G. Anderson, R. J. Salawitch, D. W. Fahey, E. L. Woodbridge, E. R. Keim, R. S. Gao, C. R. Webster, R. D. May, D. W. Toohey, L. M. Avallone, M. H. Proffitt, M. Loewenstein, J. R. Podolske, K. R. Chan and S. C. Wofsy, Removal of stratospheric $\mathrm{O}_{3}$ by radicals: in situ measurements of $\mathrm{OH}, \mathrm{HO}_{2}, \mathrm{NO}, \mathrm{NO}_{2}, \mathrm{ClO}$, and BrO, Science, 1994, 266, 398-404.

62 D. L. Solomon, K. P. Bowman and C. R. Homeyer, Tropopausepenetrating convection from three-dimensional gridded NEXRAD data, J. Appl. Meteor. Climatol., 2016, 55, 465-478.

63 O. B. Toon, H. Maring, J. Dibb, R. Ferrare, D. J. Jacob, E. J. Jensen, Z. J. Luo, G. G. Mace, L. L. Pan, L. Pfister, K. H. Rosenlof, J. Redemann, J. S. Reid, H. B. Singh, A. M. Thompson, R. Yokelson, P. Minnis, G. Chen, K. W. Jucks and A. Pszenny, Planning, implementation, and scientific goals of the studies of emissions and atmospheric composition, clouds and climate coupling by regional surveys (SEAC ${ }^{4} \mathrm{RS}$ ) field mission: planning $\mathrm{SEAC}^{4} \mathrm{RS}$, J. Geophys. Res.: Atmos., 2016, 121, 4967-5009.

64 C. R. Homeyer and M. R. Kumjian, Microphysical characteristics of overshooting convection from polarimetric radar observations, J. Atmos. Sci., 2015, 72, 870-891.

65 T. P. Marcy, D. W. Fahey, R. S. Gao, P. J. Popp, E. C. Richard, T. L. Thompson, K. H. Rosenlof, E. A. Ray, R. J. Salawitch,
C. S. Atherton, D. J. Bergmann, B. A. Ridley, A. J. Weinheimer, M. Loewenstein, E. M. Weinstock and M. J. Mahoney, Quantifying stratospheric ozone in the upper troposphere with in situ measurements of HCl, Science, 2004, 304, 261.

66 M. J. Schwartz, W. G. Read, M. L. Santee, N. J. Livesey, L. Froidevaux, A. Lambert and G. L. Manney, Convectively injected water vapor in the North American summer lowermost stratosphere, Geophys. Res. Lett., 2013, 40, 2316-2321.

67 W. J. Randel, E. Moyer, M. Park, E. Jensen, P. Bernath, K. Walker and C. Boone, Global variations of HDO and $\mathrm{HDO} / \mathrm{H}_{2} \mathrm{O}$ ratios in the upper troposphere and lower stratosphere derived from ACE-FTS satellite measurements, J. Geophys. Res., 2012, 117, D06303.

68 D. S. Sayres, L. Pfister, T. F. Hanisco, E. J. Moyer, J. B. Smith, J. M. St. Clair, A. S. O'Brien, M. F. Witinski, M. Legg and J. G. Anderson, Influence of convection on the water isotopic composition of the tropical tropopause layer and tropical stratosphere, J. Geophys. Res., 2010, 115, D00J20.

69 M. J. Alexander, J. Gille, C. Cavanaugh, M. Coffey, C. Craig, T. Eden, G. Francis, C. Halvorson, J. Hannigan, R. Khosravi, D. Kinnison, H. Lee, S. Massie, B. Nardi, J. Barnett, C. Hepplewhite, A. Lambert and V. Dean, Global estimates of gravity wave momentum flux from high resolution dynamics limb sounder observations, J. Geophys. Res., 2008, 113, D15S18.

70 A. C. Maycock, K. P. Shine and M. M. Joshi, The temperature response to stratospheric water vapour changes, Q. J. $R$. Meteorol. Soc., 2011, 137, 1070-1082.

71 J. A. Dykema, D. W. Keith and F. N. Keutsch, Improved aerosol radiative properties as a foundation for solar geoengineering risk assessment, Geophys. Res. Lett., 2016, 43, 7758-7766.

72 T. R. Koby, PhD thesis, Development of a trajectory model for the analysis of stratospheric water vapor, Harvard Univ, Cambridge, MA, 2016.

73 A. E. Dessler and S. C. Sherwood, Effect of convection on the summertime extratropical lower stratosphere, J. Geophys. Res., 2004, 109, D23301.

74 Y. Sun and Y. Huang, An examination of convective moistening of the lower stratosphere using satellite data, Earth Space Sci., 2015, 2, 320-330.

75 W. J. Randel, K. Zhang and R. Fu, What controls stratospheric water vapor in the $\mathrm{NH}$ summer monsoon regions?, J. Geophys. Res.: Atmos., 2015, 120, 7988-8001.

76 D. E. Hunton, A. A. Viggiano, T. M. Miller, J. O. Ballenthin, J. M. Reeves, J. C. Wilson, S.-H. Lee, B. E. Anderson, W. H. Brune, H. Harder, J. B. Simpas and N. Oskarsson, In situ aircraft observations of the 2000 Mt. Hekla volcanic cloud: composition and chemical evolution in the Arctic lower stratosphere, J. Volcanol. Geotherm. Res., 2005, 145, 23-34.

77 W. I. Rose, G. A. Millard, T. A. Mather, D. E. Hunton, B. Anderson, C. Oppenheimer, B. F. Thornton, T. M. Gerlach, A. A. Viggiano, Y. Kondo, T. M. Miller and J. O. Ballenthin, Atmospheric chemistry of a 33-34 hour old volcanic cloud from Hekla Volcano (Iceland): insights from direct sampling 
and the application of chemical box modeling, J. Geophys. Res., 2006, 111, D20206.

78 G. A. Millard, T. A. Mather, D. M. Pyle, W. I. Rose and B. Thornton, Halogen emissions from a small volcanic eruption: modeling the peak concentrations, dispersion, and volcanically induced ozone loss in the stratosphere, Geophys. Res. Lett., 2006, 33, L19815.

79 W. G. Mankin and M. T. Coffey, Increased stratospheric hydrogen chloride in the El Chichon cloud, Science, 1984, 226, 170-172.

80 A. Cadoux, B. Scaillet, S. Bekki, C. Oppenheimer and T. H. Druitt, Stratospheric Ozone destruction by the Bronze-Age Minoan eruption (Santorini Volcano, Greece), Sci. Rep., 2015, 5, 12243.

81 C. M. Vidal, N. Métrich, J.-C. Komorowski, I. Pratomo, A. Michel, N. Kartadinata, V. Robert and F. Lavigne, The
1257 Samalas eruption (Lombok, Indonesia): the single greatest stratospheric gas release of the Common Era, Sci. Rep., 2016, 6, 34868.

82 S. Kutterolf, T. H. Hansteen, A. Freundt, H. Wehrmann, K. Appel, K. Krüger and W. Pérez, Bromine and chlorine emissions from Plinian eruptions along the Central American Volcanic Arc: from source to atmosphere, Earth Planet. Sci. Lett., 2015, 429, 234-246.

83 S. Kutterolf, T. H. Hansteen, K. Appel, A. Freundt, K. Kruger, W. Perez and H. Wehrmann, Combined bromine and chlorine release from large explosive volcanic eruptions: a threat to stratospheric ozone?, Geology, 2013, 41, 707-710.

84 S. A. Carn, L. Clarisse and A. J. Prata, Multi-decadal satellite measurements of global volcanic degassing, J. Volcanol. Geotherm. Res., 2016, 311, 99-134. 